\title{
Testes and brain gene expression in precocious male and adult maturing Atlantic salmon (Salmo salar)
}

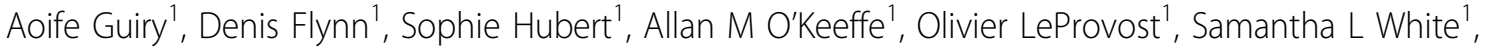 \\ Patrick F Forde ${ }^{1}$, Pamela Davoren ${ }^{1}$, Benoit Houeix ${ }^{1}$, Terry J Smith¹, Deirdre Cotter ${ }^{2}$, Noel P Wilkins ${ }^{1}$, \\ Michael T Cairns ${ }^{1 *}$
}

\begin{abstract}
Background: The male Atlantic salmon generally matures in fresh water upon returning after one or several years at sea. Some fast-growing male parr develop an alternative life strategy where they sexually mature before migrating to the oceans. These so called 'precocious' parr or 'sneakers' can successfully fertilise adult female eggs and so perpetuate their line. We have used a custom-built cDNA microarray to investigate gene expression changes occurring in the salmon gonad and brain associated with precocious maturation. The microarray has been populated with genes selected specifically for involvement in sexual maturation (precocious and adult) and in the parr-smolt transformation.
\end{abstract}

Results: Immature and mature parr collected from a hatchery-reared stock in January were significantly different in weight, length and condition factor. Changes in brain expression were small - never more than 2-fold on the microarray, and down-regulation of genes was much more pronounced than up-regulation. Significantly changing genes included isotocin, vasotocin, cathepsin D, anamorsin and apolipoprotein E. Much greater changes in expression were seen in the testes. Among those genes in the testis with the most significant changes in expression were anti-Mullerian hormone, collagen 1A, and zinc finger protein (Zic1), which were down-regulated in precocity and apolipoproteins $\mathrm{E}$ and C-1, lipoprotein lipase and anti-leukoproteinase precursor which were upregulated in precocity. Expression changes of several genes were confirmed in individual fish by quantitative PCR and several genes (anti-Mullerian hormone, collagen 1A, beta-globin and guanine nucleotide binding protein (G protein) beta polypeptide 2-like 1 (GNB2L1) were also examined in adult maturing testes. Down-regulation of anti-Mullerian hormone was judged to be greater than 160-fold for precocious males and greater than 230-fold for November adult testes in comparison to July testes by this method. For anti-Mullerian hormone and guanine nucleotide binding protein beta polypeptide 2-like 1 expression changes in precocious males mirrored mature adults (November) but for collagen 1A and beta-globin the pattern was more complex.

Conclusions: Expression changes in the fish brain during the process of precocious sexual maturation were small compared to those in the testes. Microarray analysis suggested down-regulation of housekeeping functions and up-regulation of a small number of specific processes. Transcriptional changes in the testes were much more pronounced with anti-Mullerian hormone playing a major role. Expression profiles for mature parr and maturing adult testes indicate subtle differences in gene expression between these two related groups.

\footnotetext{
* Correspondence: michael.cairns@nuigalway.ie

${ }^{1}$ National University of Ireland, Galway, University Road, Galway, Ireland
} 


\section{Background}

Alternative reproduction tactics (ARTs) enable fish to exploit a wide spectrum of resources and to respond to conditions such as an imbalance of sexes in the population [1]. The opportunity for ARTs in fishes arises largely as a consequence of external fertilisation. Access to eggs for fertilisation can be by adult males or alternatively by precociously mature parr variously described as 'satellite males' or 'sneakers' [2,3]. The mature parr succeed mainly through speed or through being inconspicuous to adult males who might otherwise drive them off. The approach taken by an individual fish is believed to depend on the balance of energetic cost against reproductive payoff. The energetic cost of adult male reproduction in salmon is very high and few adults return to reproduce a second time $[4,5]$. However, the payoff is also high because an adult male can dominate an egg-laying female and almost all offspring are sired by that male. The energetic cost for a juvenile male (precocious male) may be much less but only a small number of eggs may be fertilised by that male.

The decision to mature precociously or remain immature for another winter has been modelled as a threshold trait $[6,7]$. A threshold level which takes into account parameters such as growth rate, body size and condition must be reached before the parr can mature. Both genetic [8] and environmental factors [9], which include social structure, are believed to play a part in attaining this threshold. For example, where environmental factors have been largely excluded by removing wild fish to a hatchery, the proportion of mature parr offspring was related to the source river of the parents suggesting involvement of a genetic component [10]. However, an environmental component was intimated by a study that showed tributaries of a single river had size thresholds for precocity that depended on the altitude of the tributary [11]. Precocity levels of $20 \%$ have been reported in Scotland [12] though levels as high as $65 \%$ have been reported for more southerly rivers [13] possibly as a result of the warmer waters and faster growth of the fish.

In cultured salmonids levels of precocity can vary depending on the genetic stock but high levels lead to reduced productivity and can present a health risk to the fish population through the negative effect of testosterone on immune function [14]. In the wild, fish that fortuitously find a better food source may grow faster and become socially dominant. Hatchery-reared fish are well fed yet growth and social hierarchy are still factors that influence the choice to mature precociously or undergo the parrsmolt transformation. In Ireland, wild Atlantic salmon generally remain in fresh water until the parr-smolt transformation at year $2+$ or later [15]. They feed heavily in the marine environment for one year (grilse) or several years (multi-sea winter; MSW) before returning to their native streams to spawn. In the hatchery environment the majority of salmon parr are expected to smolt at year 1+: populations generally show a bimodal growth distribution in the previous autumn (year $0+$ ) with larger fish preparing to smolt while the minor group of smaller fish will smolt a year later [16].

The juvenile male parr has three possible life trajectories: it can remain immature, it can undergo the parrsmolt transformation, or it can mature precociously prior to the parr-smolt transformation. Precocious parr are more likely to be those juvenile parr that have grown rapidly; they then transfer their energies into gonad development at the expense of bodily growth. At some point the balance will change when the immature parr out-grow the sexually mature parr and the social structure may again change [5].

The brain-pituitary-gonad (BPG) axis is the key regulator of sexual maturation. Neuron stimulation of the brain leads to stimulation of the pituitary through gonadotropin releasing hormone (GnRH) which releases relevant hormones, such as follicle stimulating hormone (FSH) and luteinising hormone ( $\mathrm{LH})$ into the blood plasma for transport to the effector tissue. In the testes LH induces the production of testosterone which then affects various aspects of male physiology, secondary sexual characteristics and behaviour. In this study our goal was to develop a comprehensive picture of gene expression in the gonad and brain in precocious males, and compare mature parr testes to adult testes. However, in an extension to this study, we also aimed to develop resources and investigate interactions between sexual maturation and the parr-smolt transformation. There are now several genomic resources available to the Atlantic salmon research community. The Canadian GRASP project [17], the Norwegian Salmon Genome Project http://www.salmongenome.no and the EU SALGENE project http://www.salmongenome.no/cgi-bin/ sgp.cgi all have provided large numbers of cDNA sequences for the DNA databases. We have developed a new Atlantic salmon cDNA microarray that is specifically targeted at sexual maturation and the parr-smolt transformation: this is the first description of this array. The focus was on generating single tissue libraries of key transition stages from subtracted salmon cDNA libraries: we have observed that novel regulated genes are more likely to be represented in these subtracted libraries between two conditions than in single condition cDNA libraries [18].

Adult maturation differs from precocious maturation in a number of important aspects; adult fish mature in fresh water after a sustained period of growth at sea having undergone the parr-smolt transformation either one or several years earlier. We have therefore also 
considered whether some of the identified genes differed in expression between precocious males and returning males.

\section{Results and Discussion}

Microarray analysis of precocious testes

Non-precocious parr were significantly longer and heavier than precocious parr (Figure 1). The difference in weight (using an unpaired t-test) and length (using a Mann Whitney test) in the two populations were both shown to be significant $(P<0.0001)$. It is generally accepted that males which grow at a faster rate are more likely to become precocious than slower growing male parr [19]. However, once this life history choice has been made (certainly by January), sexual maturation proceeds at the expense of somatic growth.

Total RNA, isolated from precocious and non-precocious parr testes was shown to be intact by both Northern blot and analysis using the Agilent 2100 Bioanalyser. All samples used subsequently had RIN values between 9 and 10 [20]. Suppression Subtractive Hybridisation (SSH) was used to enrich for genes differentially expressed during the process of precocious maturation [21]. Two pairs of libraries related directly to this study of precocity (testes and brain) while other SSH libraries related to different tissues (e.g. hypothalamus and pituitary) or different aspects of sexual maturation (e.g. adult maturing ovary). Furthermore, there was a selection of testes full-length (not SSH) and undifferentiated gonad
(SSH) clones from other sources both salmon [22] and trout (McMeel and Guiguen, unpublished).

Three pools each of four individual precocious testes were compared by microarray analysis to three pools of ten pooled non-precocious testes (Figure 2a). Although not allowing a direct comparison of individual fish this loop design provided scope to look at individual pools yet maintain a compact design with dye balance and a minimum number of hybridisations [23,24]. This data series has GEO accession number GSE16721. A list of significant differentially expressed clones $(\mathrm{P}<0.05$ and using the Benjamini and Hochberg multiple test correction) was compiled. This list of 500 clones was cut down to approximately 65 for sequencing based primarily on fold changes in expression (Additional file 1: table s1). A shortened version of this table is provided as Table 1. Most clones (75\%) showed homology to known database sequences, however $17 \%$ were found to have homology to unidentified ESTs and 8\% 'failed' sequencing. 'Failed' sequences encompassed short sequences (e.g. too short to identify by homology searches), poor sequences (e.g. poly Ts and mixed clones), and no sequence (template problem). Between pool variation was also examined in LIMMA. For the P pools 484 of the 500 top clones were identified in all three pools and 499 in at least two of the pools. For the NP pools 499 of the top 500 clones were identified in all three pools and all 500 in at least two of the pools. This indicated that no individual sample was excessively

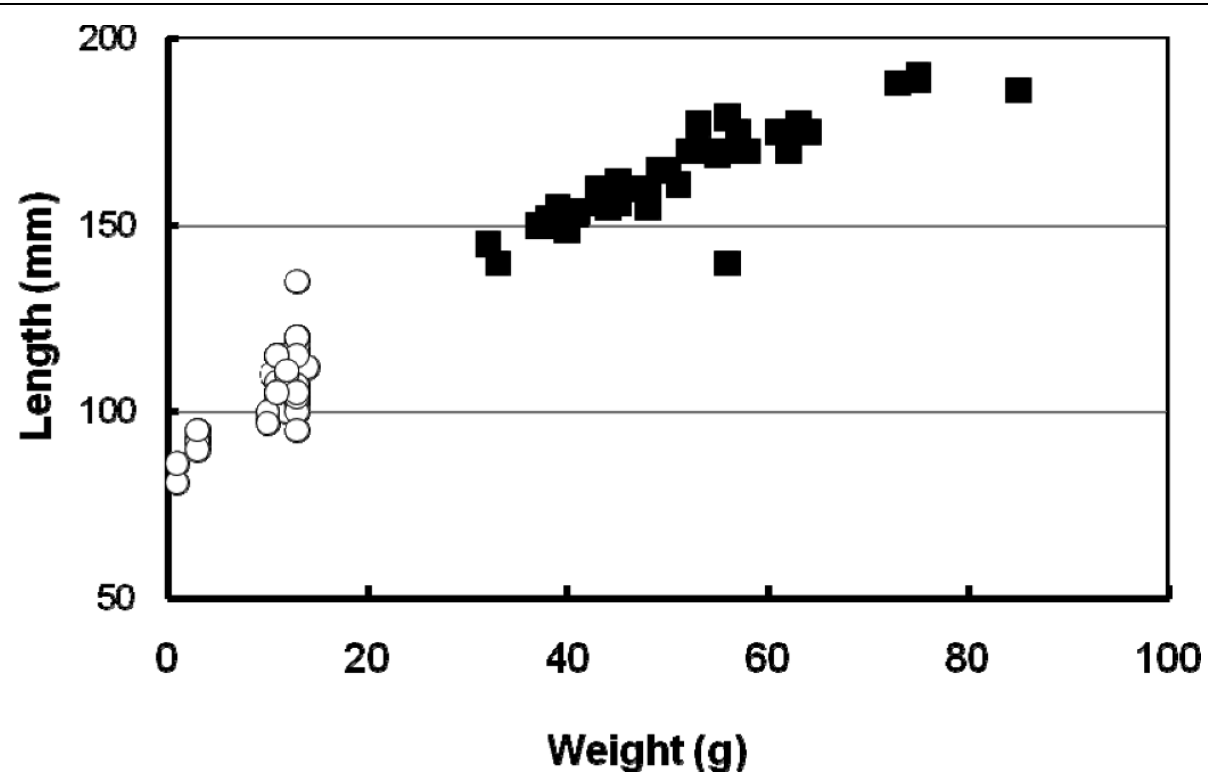

Figure 1 Fish sample populations for precocity and non-precocity. Precocious fish (empty circles) and non-precocious fish (full squares) were weighed and measured. Fish (25 of both precocious and non-precocious) were sampled on 15 Jan 2003. The difference in weight (using an unpaired t-test) and length (using a Mann Whitney test) in the two populations were both shown to be extremely significant $(P<0.0001)$. 


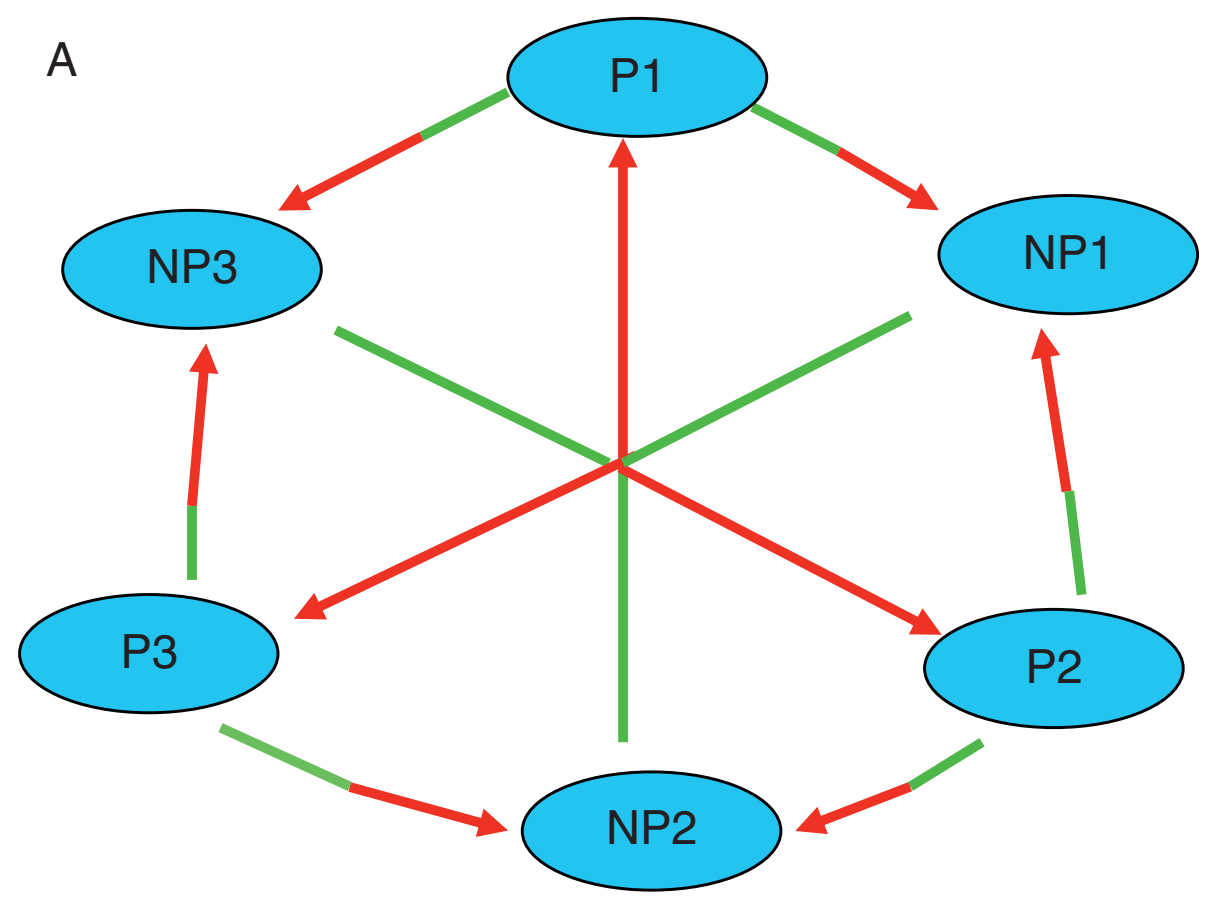

B

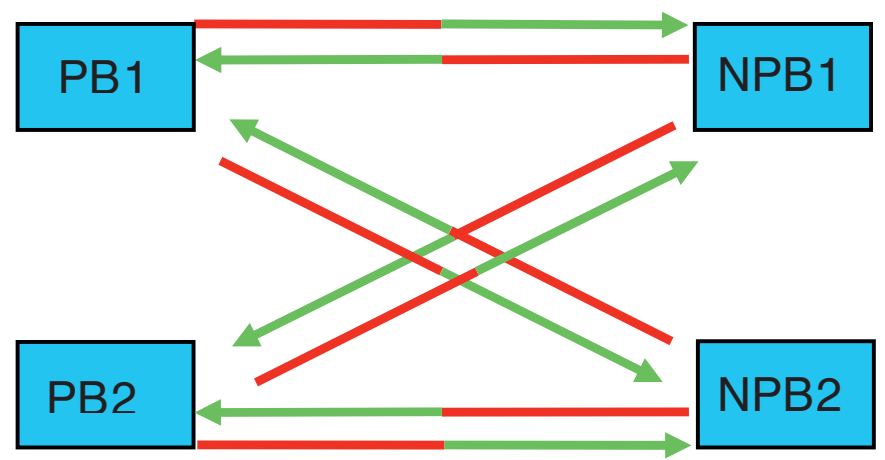

Figure 2 Hybridisation designs for testes and brain microarray. (a) Testes sample pools were hybridised using a loop design. Three precocious pools (P1-P3) each of four individuals were hybridised to three non-precocious pools (NP1-NP3) each of ten individuals. Each sample pool at the tail of the arrow (green) was Cy3-labelled and that at the arrowhead (red) was Cy5-labelled. Each pool was hybridised three times and at least once with each of the Cy5 or Cy3 dyes to maintain dye balance. Analysis was with LIMMA software. (b) Brain samples were hybridised directly using pools of five individuals. Pool labelling was as detailed above. Two separate pools of precocious brains (PB1 and PB2) were each compared directly to two separate pools of non-precocious brains (NPB1 and NPB2). All hybridisations include dye swaps. Analysis was with LIMMA software.

influencing the overall precocious versus non-precocious comparison.

From Table 1 it would appear that the protein translational machinery has been substantially down-regulated in precocious males: genes for the heat shock proteins (Hsp70a and Hsp90b), the elongation factors (EF-1alpha, EF-1gamma and EF-2) and the ribosomal proteins (RpL5, RpL8 and RpS5) attest to this. Cathepsin B was up-regulated in the maturing testes as too was an antileukoproteinase similar to trout ovulatory protein (OVP-2): this suggests regulated re-structuring of the gonad in a similar manner to what happens in the ovary. Apolipoprotein (Apo) $\mathrm{E}$ is involved in lipoprotein uptake and processing; it is a carrier for lipid into the cells and subsequently mediates the exchange of lipids and cholesterol in LDL. Lipoprotein lipase (Lpl), which digests plasma lipoproteins releasing lipids which apolipoproteins including ApoE can internalize [25], was also 
Table 1 Differentially expressed genes of the testis during precocious maturation.

\begin{tabular}{|c|c|c|c|c|c|}
\hline${ }^{1}$ GenBank Accession No. & ${ }^{2}$ Up or Down & Fold & Gene name & E-value & $\begin{array}{l}{ }^{3} \text { Accession No. of Hit } \\
\text { (Unigene if appropriate) }\end{array}$ \\
\hline GO944178 & $\downarrow$ & 2.0 & Alpha globin 1 & 0.0 & NM_001124550 \\
\hline GO944180 & $\downarrow$ & 1.9 & Alpha-4 globin & $4 \mathrm{E}-178$ & BT050340 \\
\hline GO256596 & $\uparrow$ & 5.4 & Anti-leukoproteinase precursor/OVP-2 & $6 \mathrm{E}-112$ & TC64926 \\
\hline GO256601 & $\downarrow$ & 7.2 & Anti-mullerian hormone & 0 & NM_001123585 \\
\hline GO256604 & $\uparrow$ & 16.4 & Apolipoprotein C-1 & $1 \mathrm{E}-153$ & NM_001141362 \\
\hline CR943959 & $\uparrow$ & 5.7 & Apolipoprotein C-1 & $7 \mathrm{E}-129$ & NM_001141362 \\
\hline CR944033 & $\uparrow$ & 14.9 & Apolipoprotein C-1 & $7 \mathrm{E}-129$ & NM_001141362 \\
\hline GO256602 & $\uparrow$ & 14.0 & Apolipoprotein C-1 & $2 \mathrm{E}-141$ & NM_001141362 \\
\hline$\overline{n / a}$ & $\uparrow$ & 6.6 & Apolipoprotein E & $\mathrm{n} / \mathrm{a}$ & CA050208 \\
\hline GO256613 & $\uparrow$ & 2.9 & Apolipoprotein E & 0.0 & CB502338 (Ssa30932) \\
\hline GO256585 & $\downarrow$ & 2.6 & Beta globin & 0.0 & AY026061 \\
\hline G0944177 & $\downarrow$ & 3.2 & Beta globin & 0.0 & YO8923 \\
\hline FD425634 & $\downarrow$ & 1.7 & Beta-2 microglobulin & $1 E-64$ & TC33956 \\
\hline GO256603 & $\uparrow$ & 3.6 & Cathepsin B & $6 \mathrm{E}-134$ & TC55653 \\
\hline GO256605 & $\uparrow$ & 2.7 & Cathepsin B & $6 \mathrm{E}-134$ & TC55653 \\
\hline FD425625 & $\downarrow$ & 3.7 & Collagen $1 \mathrm{~A} 2$ & $6 \mathrm{E}-33$ & TC37297 \\
\hline FD425605 & $\downarrow$ & 3.7 & Collagen $1 \mathrm{~A} 2$ & $9 \mathrm{E}-100$ & TC22424 \\
\hline FD425653 & $\downarrow$ & 4.5 & Collagen $1 \mathrm{~A} 2$ & $9 \mathrm{E}-100$ & TC22424 \\
\hline GO256584 & $\downarrow$ & 1.8 & Elongation factor EF-1 alpha & 0.0 & AF498320 \\
\hline$\overline{n / a}$ & $\downarrow$ & 1.8 & Elongation factor EF-1 alpha & $\mathrm{n} / \mathrm{a}$ & CB502673 (Ssa.30552) \\
\hline $\mathrm{B} \mid 468075$ & $\downarrow$ & 2.4 & Elongation factor EF-1 gamma & $1 \mathrm{E}-121$ & TC41574 \\
\hline $\mathrm{n} / \mathrm{a}$ & $\downarrow$ & 1.5 & Elongation factor EF-2 & $\mathrm{n} / \mathrm{a}$ & DV196880 (Omy.33489) \\
\hline FD425597 & $\uparrow$ & 2.9 & GDP-mannose 4, 6-dehydratase & $2 \mathrm{E}-73$ & TC26943 \\
\hline FD425627 & $\uparrow$ & 1.1 & Glutamine synthetase & $3 E-44$ & TC28369 \\
\hline FD425678 & $\downarrow$ & 1.23 & Glutathione S-transferase & $6 \mathrm{E}-98$ & TC117527 \\
\hline G0944125 & $\downarrow$ & 2.1 & Glutathione S-transferase & $8 \mathrm{E}-116$ & TC111174 \\
\hline GT222009 & $\downarrow$ & 1.6 & Growth hormone 1 precursor & 0.0 & CX719563 \\
\hline GO256590 & $\downarrow$ & 2.6 & Guanine nucleotide binding protein/RACK1 & 0.0 & BT043532 \\
\hline GT222008 & $\uparrow$ & 1.6 & Heat shock protein hsp70a & 0.0 & NM_001124232 \\
\hline $\mathrm{n} / \mathrm{a}$ & $\downarrow$ & 1.7 & Heat shock protein hsp90 beta & $\mathrm{n} / \mathrm{a}$ & AJ632154 (Ssa.1060) \\
\hline B/468080 & $\downarrow$ & 1.4 & Heat shock protein hsp90 beta & $\mathrm{n} / \mathrm{a}$ & $\mathrm{B} \mid 468080$. \\
\hline FD425670 & $\downarrow$ & 1.6 & Heat shock protein hsp90 beta & $4 \mathrm{E}-24$ & TC22349 \\
\hline FD425588 & $\downarrow$ & 2.3 & Heat shock protein hsp90 beta & 0 & AF135117 \\
\hline $\mathrm{n} / \mathrm{a}$ & $\uparrow$ & 1.9 & Gonadotropin-releasing hormone receptor & $\mathrm{n} / \mathrm{a}$ & CA046044 (Omy.8048) \\
\hline GO256593 & $\uparrow$ & 2.7 & Lipoprotein lipase & $8 \mathrm{E}-77$ & TC52451 \\
\hline GO256597 & $\uparrow$ & 2.1 & Nuclear Protein-1 & 0 & BT048359 \\
\hline GO256611 & $\uparrow$ & 2.6 & Proopiomelanocortine B & $8 \mathrm{E}-81$ & DQ508935 \\
\hline GT145199 & $\uparrow$ & 2.3 & Retinoic acid receptor responder protein 3 & 0.0 & EG875900 (Ssa.836) \\
\hline$\overline{\mathrm{n} / \mathrm{a}}$ & $\uparrow$ & 2.0 & 16S Ribosomal rRNA & 0.0 & DQ864465 \\
\hline GT145267 & $\downarrow$ & 2.4 & Ribosomal protein L8 & $7 E-59$ & AY957563 \\
\hline FD425672 & $\downarrow$ & 2.4 & Ribosomal protein S5 & $4 \mathrm{E}-89$ & AF543539 \\
\hline G0944179 & $\downarrow$ & 1.7 & Similar to CD209 antigen-like protein D & 0.012 & BT048497 \\
\hline GO256582 & $\downarrow$ & 7.9 & Similar to collagen $1 \mathrm{~A} 3$ & $2 \mathrm{E}-36$ & TC151122 (O.mykiss) \\
\hline GO256609 & $\uparrow$ & 1.4 & Similar to influenza virus NS1A binding protein $b$ & $7 \mathrm{E}-12$ & BC066513 \\
\hline GO256612 & $\uparrow$ & 1.3 & Similar to neural cell adhesion L1-like & $8 \mathrm{E}-151$ & TC82871 \\
\hline FD425595 & $\downarrow$ & 2.0 & Similar to ribosomal protein $\mathrm{L} 5$ & $9 \mathrm{E}-134$ & BT046397 \\
\hline
\end{tabular}


Table 1: Differentially expressed genes of the testis during precocious maturation. (Continued)

\begin{tabular}{llllll}
\hline FE963911 & $\uparrow$ & 1.4 & Similar to SIX homeobox 6 & 1E-90 & DW628904 \\
\hline GO256594 & $\downarrow$ & 6.0 & Transferrin & 3E-152 & BT045182 \\
\hline FE963864 & $\downarrow$ & 5.2 & Zinc finger protein Zic1 & 5E-143 & NM_001140488 \\
\hline
\end{tabular}

${ }^{1}$ Clones on this list may already have been sequenced in other projects (e.g. STRESSGENES). Accession numbers are given where available.

${ }^{2} \mathrm{An}$ upward arrow indicates up-regulation in precocious males

${ }^{3}$ BLAST accession numbers starting with TC indicate sequences in the TIGR database.

identified as an up-regulated gene in the precocious testes. Possibly ApoE is required for transport of cholesterol into the Leydig cell mitochondria in order to make available cholesterol for steroidogenesis or for transport of lipid needed either as a energy source or for cell membrane biosynthesis in gametogenesis [26]. AntiMullerian hormone (AMH: also known as Mullerian Inhibiting Substance) was strongly down-regulated in the precocious male testes. AMH has growth factor activity with a TGFbeta-like C-terminal domain and is known to have roles in Mullerian duct regression, sex determination, sex differentiation and gonad mesoderm development [27, 28]. Its role in testicular differentiation in fish was suggested when a spermatogenesis-preventing substance was isolated from eel [29] and further reports confirm significant regulation in other fish [30,31]. Another up-regulated gene was gonadotropinreleasing hormone receptor (GnRH-R). The expression of gonadotropin-releasing hormones $(\mathrm{GnRH})$ and their receptors in the gonads of fish and many other species has been reported previously [32] and suggests paracrine/autocrine control on gonad development. Although in fish there are multiple forms of GnRH peptides and $\mathrm{GnRH}$ receptors there appears to be one form of GnRH and GnRH-R in the gonad which varies in expression considerably depending on reproduction status [33]. Increased GnRH-R1, as reported in this study, is associated with the later stages of spermatogenesis in rainbow trout [33]. Another gene more often associated with the pituitary that shows differential expression in the testes is growth hormone $(\mathrm{GH})$. Down-regulation, as seen here, probably relates to the full maturity of these testes (January) and the higher reported levels of receptors for growth hormone in recrudescent testes [30,34]; if gene transcription is being switched off lower levels might be expected that in the immature parr where levels may be quite steady or rising in preparation for the parr-smolt transformation [35].

\section{Quantitative PCR on pooled precocious testis}

In order to confirm the findings of the microarray analysis on the testes tissue a number of genes were selected and further investigated using real-time quantitative PCR. These qPCR experiments were carried out on the same pools used for microarray hybridisations. Several potential housekeeping genes were analysed for use as a reference gene in quantitative PCR. Our goal was to identify a gene that could be reliably used as a reference in both the precocious samples and the adult maturing samples. Most of the genes examined (betaactin, glyceraldehyde-3-phosphate dehydrogenase, hypoxanthine-guanine phosphoribosyl transferase, cyclophilin and ubiquitin) were significantly differentially regulated in at least one developmental stage, but changes in succinate dehydrogenase (SD) expression levels were not significant $(\mathrm{P}>0.05)$ (Additional file 2). Relative expression was therefore calculated using the Delta Delta $C(t)$ method [36] using succinate dehydrogenase (SD) as the reference gene. Preliminary quantitative PCR experiments were set up to analyse the expression patterns of the genes from the panel using biological pools of non-precocious parr testes and precocious parr testes (Figure 3a). Nine genes were selected for qPCR based mainly on the number of times the gene was independently identified on the array and on an examination of both fold changes and levels of significance. Of the genes selected only cathepsin B showed a discrepancy between microarray analysis and qPCR. It appears that the microarray SSH clone was similar to GenBank accession no. NM_001140522 (S. salar cathepsin B) but that the qPCR primers were designed to EST EG934102. This EST is also described as 'cathepsin B' but is a different isoform - different enough that the (reverse) primer is specific for this form. It is open to speculation why one form may be down-regulated more than 2-fold (qPCR) while, as the microarray suggests, another form appears up-regulated more than 2-fold. The fold changes in differential regulation were frequently larger by qPCR than by microarray: AMH levels by microarray analysis were $\sim 6.5$-fold down-regulated in precocity yet qPCR showed the fold down-regulation to be as much as 59-fold.

\section{Quantitative PCR on individual testis}

After validation using fish pools, qRT-PCR of individual fish was carried out on a number of the genes (Figure 3b). As stated previously AMH was known to have roles in Mullerian duct regression and sex differentiation so it was 


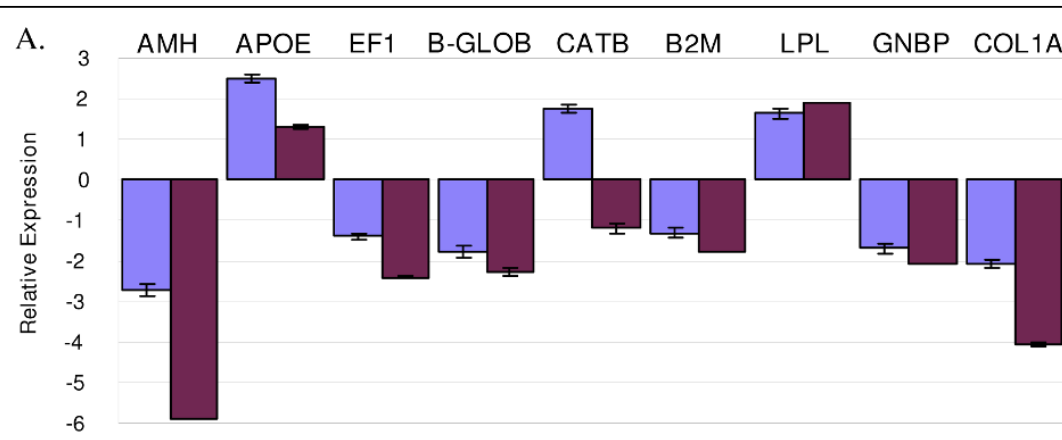

B.
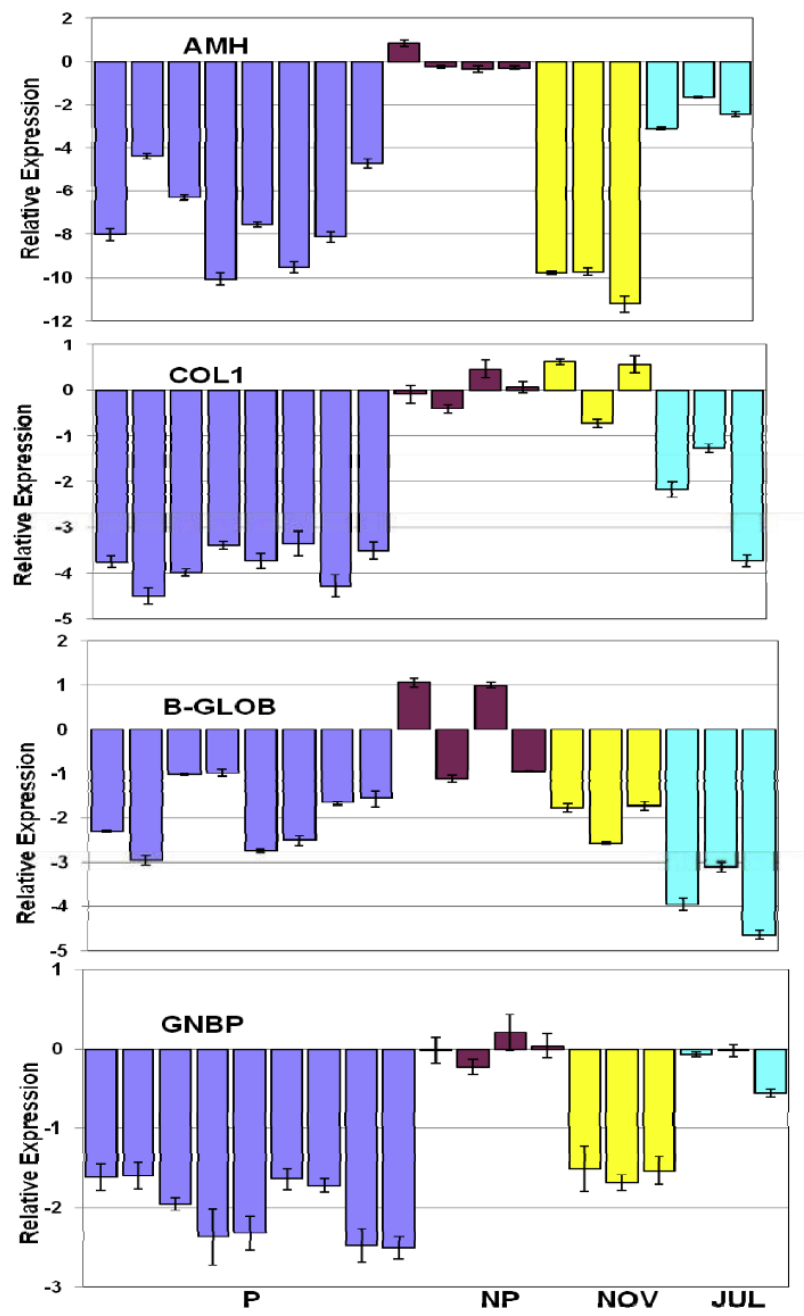

Figure 3 Microarray and qRT-PCR data for select genes in testes samples. (a) A comparison of microarray and qRT-PCR data in pooled samples. Microarray data (blue bars) for the LIMMA comparison of precocious and non-precocious testes were compared to qPCR data (red bars) for the same RNA pools that were used in the microarray analysis, i.e. pooled precocious $(n=12)$ and non-precocious $(n=30)$. Positive values are up-regulated in precocity and log2 values are plotted on a linear scale for clarity. All qPCR data was normalised using succinate dehydrogenase (SD) as reference gene. QPCR values are Means \pm SEM of triplicate measurements. Error bars are only shown on the microarray data where the gene is represented more than once in the list of significant genes. (b) qPCR of individual testes samples relating to precocity and adult maturation. Samples of precocious testes (blue bars; $n=8-9$ ), and July (turquoise bars) and November (yellow bars) maturing adults ( $\mathrm{n}$ = 3) were of individuals whereas those of non-precocious males (red bars) were 4 pools each of 10 testes. Relative expression levels are plotted as $\log 2$ values on a linear scale. Succinate dehydrogenase (SD) was the reference gene in all cases. All primers were designed to the database sequence of the identified gene (see Table 4). Values are Means \pm SEM of triplicate measurements. See Additional file 2 for some further details. AMH: Anti-Mullerian Hormone, APOE: Apolipoprotein E, EF1: Elongation Factor 1, B-GLOB: beta-globin, CATB: cathepsin B, B2M: Beta-2 microglobulin, LPL: Lipoprotein lipase, GNB2L1: Guanine nucleotide binding protein (G protein) beta polypeptide 2-like 1, COL1A: Type 1A collagen. 
an interesting candidate. Guanine nucleotide binding protein (G protein) beta polypeptide 2-like 1 (GNB2L1), also known as RACK1, plays a part in cellular signalling pathways [37] and is known to compete with Hsp90 for binding to hypoxia-inducible factor 1alpha (HIFalpha) [38]. Both alpha- and beta-globin were down-regulated in the testes in precocity and, like type 1 collagen (COL1A), they were identified more than once independently on the array. In order to add value to this data maturing adult testes sampled in July and November were also analysed: whereas November testes are likely to be almost mature (GSI 2.4), July testes will be at a much earlier stage of maturation (GSI 0.2). All expression levels were normalised to the succinate dehydrogenase reference gene (Table 2).

AMH expression in individual precocious testes was down-regulated approximately 20- to 1070-fold in different individuals. Adult maturing testes followed a similar pattern where the more mature November adults showed high levels of down-regulation (850- to 2400fold) and the less mature July adults showed only 3.1- to 8.6-fold down-regulation. There was more variability in the precocious levels of $\mathrm{AMH}$ expression than the November adults; though the number of the latter is very low (3), this might suggest that maturation is much more synchronised in the latter. AMH levels were also generally lower in the November adults than in the

Table 2 Quantitative PCR validation of microarray analysis

\begin{tabular}{|c|c|c|c|}
\hline Gene & Microarray & qPCR & qPCR \\
\hline & \multicolumn{3}{|c|}{ Testes Expression (Fold Change) } \\
\hline & $\begin{array}{c}\text { P relative to } \\
\text { NP }\end{array}$ & $\begin{array}{c}\text { P relative to } \\
\text { NP }\end{array}$ & $\begin{array}{c}\text { November relative to } \\
\text { Jul }\end{array}$ \\
\hline$\overline{\mathrm{AMH}}$ & -7.2 & -58.9 & -231.6 \\
\hline ApoE & +4.8 & +2.5 & +1.2 \\
\hline $\mathrm{EF} 1 \alpha$ & -1.8 & -5.3 & -3.7 \\
\hline$\beta$-Glob & -2.9 & -4.9 & +3.7 \\
\hline Cat B & +3.2 & -2.3 & 1.0 \\
\hline$\beta 2 \mathrm{M}$ & -1.7 & -3.4 & -2.1 \\
\hline LPL & +2.7 & +3.7 & +2.9 \\
\hline GNBP & -2.6 & -4.3 & -2.6 \\
\hline Col 1A & -4.0 & -16.7 & +5.8 \\
\hline \multicolumn{4}{|c|}{ Brain Expression } \\
\hline ApoE & -1.3 & -1.4 & \\
\hline$\beta$-Glob & -1.5 & +1.3 & \\
\hline IT-1 & $n / a$ & -9.0 & \\
\hline IT-2 & -1.5 & -9.1 & \\
\hline $\mathrm{MCH}$ & +1.2 & +1.7 & \\
\hline $02 \mathrm{~A} 07$ & -1.3 & +1.1 & \\
\hline $04 \mathrm{H} 01^{1}$ & +1.5 & +1.2 & \\
\hline 22D02 & +1.3 & +3.0 & \\
\hline
\end{tabular}

${ }^{1}$ Clone included a microsatellite precocious fish - five of the seven precocious males had levels much higher than the three November adults.

Guanine nucleotide binding protein ( $G$ protein) beta polypeptide 2-like 1 (GNB2L1) showed a similar pattern of expression to $\mathrm{AMH}$, with down-regulation in precocious parr and in November adults compared to nonprecocious parr and July adults though fold changes in expression level were small, approximately $1 / 10$ those of AMH. Collagen (1A) and beta-globin also showed down-regulation in precocious parr but July adult levels were lower than November adults. Statistical analysis by Kruskal-Wallis and Dunn's Multiple Comparisons tests demonstrated that expression in the precocious testes was significantly different from that in the non-precocious testes for all genes $(\mathrm{P}<0.001$; beta-globin beta $\mathrm{P}$ $<0.01$ ) as it was also for July v November maturing adults. For AMH and GNB2L1 expression in precocious testes was similar to that of adult November testes and expression in non-precocious testes was similar to that of adult July testes $(\mathrm{P}>0.05)$. For beta-globin non-precocious testes were significantly different from all other testes types $(\mathrm{P}<0.01)$.

\section{Microarray analysis of precocious brains}

Precocity effects on brain gene expression were also measured by microarray analysis. Here two pools of five precocious brains were compared directly to two pools of five non-precocious parr brains (Figure 2b). Data was analysed with LIMMA to determine which genes were differentially regulated between the pools for the two tissue types (PB v NPB). This data series has GEO accession number GSE16720. An initial list of 487 clones $(\mathrm{P}<0.05)$ was reduced to a top 100 clones (on $\mathrm{P}$-value) and 66 that were sequenced are presented (Additional file 3: table s2). A shortened version of this table is provided as Table 3 . The fold changes in expression level were small compared to changes in testes expression with a maximum of 1.7 fold up-regulation for an unknown EST and 1.9 fold down-regulation for vasotocin-1. Approximately 50\% of the top 66 clones were derived from brain-related libraries. Alpha-globin was identified five times on the array and beta-globin three times: both genes showed consistent down-regulation of 1.4 fold and 1.5 fold respectively. Other genes that were identified more than once included beta-tubulin $(2 \times)$, elongation factor 1 alpha $(3 \times)$, apolipoprotein $\mathrm{E}$ $(2 \times)$, suppressor of G2 allele of SKP1 $(2 \times)$ and vasotocin-1 $(2 \times)$; the only inconsistency was that one copy of G2 allele of SKP1 was up-regulated $1.4 \times$ and the other copy was down-regulated $1.3 \times$. Several of the clones represented definite ESTs which were highly homologous to other ESTs in the NCBI and TIGR databases but for which identities were ambiguous. Again between pool variation was examined in LIMMA. Of the 142 
Table 3 Differentially expressed genes of the brain during precocious maturation.

\begin{tabular}{|c|c|c|c|c|c|}
\hline${ }^{1}$ GenBank Accession No. & ${ }^{2}$ Up or Down & Fold & Gene name & E-value & $\begin{array}{l}{ }^{3} \text { Accession No. of Hit } \\
\text { (Unigene if appropriate) }\end{array}$ \\
\hline BE518469 & $\downarrow$ & 1.5 & Alpha-globin 1 & 0.0 & NM_001124550 \\
\hline GO944156 & $\downarrow$ & 1.3 & Alpha-globin 1 & 0.0 & NM_001124550 \\
\hline BE518469 & $\downarrow$ & 1.3 & Alpha-globin 1 & 0.0 & NM_001124550 \\
\hline GR209362 & $\downarrow$ & 1.4 & Alpha-globin 4 & $5 \mathrm{E}-101$ & ВТ050340 \\
\hline G0944180 & $\downarrow$ & 1.5 & Alpha-globin 4 & $4 \mathrm{E}-178$ & BT050340 \\
\hline GT145313 & $\downarrow$ & 1.2 & Anamorsin & 0.0 & BT043538 \\
\hline $\mathrm{n} / \mathrm{a}$ & $\downarrow$ & 1.3 & Apolipoprotein E & $\mathrm{n} / \mathrm{a}$ & CA050208 Ssa.30932 \\
\hline GO256613 & $\downarrow$ & 1.3 & Apolipoprotein E & $2 \mathrm{E}-123$ & TC91898 \\
\hline BE518484 & $\downarrow$ & 1.3 & Beta-2 microglobulin & 0.0 & NM_001123699 \\
\hline $\mathrm{n} / \mathrm{a}$ & $\downarrow$ & 1.2 & Beta-actin & $\mathrm{n} / \mathrm{a}$ & NM_001123525 \\
\hline GO256610 & $\uparrow$ & 1.2 & Beta-catenin interacting protein 1 & 0.0 & NM_001139923 \\
\hline GO256585 & $\downarrow$ & 1.5 & Beta globin & 0.0 & AY026061 \\
\hline GO944177 & $\downarrow$ & 1.4 & Beta globin & 0.0 & YO8923 \\
\hline BE518474 & $\downarrow$ & 1.5 & Beta-globin & 0.0 & NM_001123666 \\
\hline $\mathrm{n} / \mathrm{a}$ & $\downarrow$ & 1.2 & Beta-tubulin & $\mathrm{n} / \mathrm{a}$ & NM_001139793 \\
\hline GO256580 & $\downarrow$ & 1.3 & Beta-tubulin & $2 \mathrm{E}-103$ & NM_001140292 \\
\hline CR943970 & $\downarrow$ & 1.3 & Beta tubilin & $8 \mathrm{E}-54$ & BT058720 \\
\hline $\mathrm{n} / \mathrm{a}$ & $\downarrow$ & 1.3 & Cathepsin D & $\mathrm{n} / \mathrm{a}$ & NM_001124711 \\
\hline FE963874 & $\downarrow$ & 1.2 & Cofilin 2 & $2 \mathrm{E}-94$ & BT060221 \\
\hline $\mathrm{n} / \mathrm{a}$ & $\downarrow$ & 1.2 & Elongation factor EF-1 alpha & $\mathrm{n} / \mathrm{a}$ & CB502673 \\
\hline GO256584 & $\downarrow$ & 1.2 & Elongation factor EF-1 alpha & $4 \mathrm{E}-152$ & BT058929 \\
\hline GO256588 & $\downarrow$ & 1.2 & Elongation factor EF-1 alpha & 0.0 & NM_001141909 \\
\hline GO944131 & $\downarrow$ & 1.1 & Ferritin $\mathrm{H}-1$ & $3 \mathrm{E}-112$ & NM_001124547 \\
\hline $\mathrm{n} / \mathrm{a}$ & $\downarrow$ & 1.2 & GAPDH & n/a & NM_001123561 \\
\hline$n / a$ & $\downarrow$ & 1.2 & GAPDH & $\mathrm{n} / \mathrm{a}$ & NM_001123561 \\
\hline $\mathrm{n} / \mathrm{a}$ & $\downarrow$ & 1.2 & Glutamine synthetase & $3 E-10$ & NM_001124314 \\
\hline GO256590 & $\downarrow$ & 1.2 & $\begin{array}{l}\text { Guanine nucleotide binding protein, } \\
\text { beta polypeptide 2-like } 1\end{array}$ & 0.0 & BT059305 \\
\hline GT222010 & $\uparrow$ & 1.2 & Heterogeneous nuclear ribonucleoprotein $A / B$ & $2 \mathrm{E}-106$ & BT045277 \\
\hline $\mathrm{n} / \mathrm{a}$ & $\uparrow$ & 1.2 & Hydroxysteroid 11-beta dehydrogenase & $\mathrm{n} / \mathrm{a}$ & AB104415 \\
\hline BE518475 & $\uparrow$ & 1.2 & Interleukin enhancer binding factor 2 & $1 \mathrm{E}-70$ & BT045275 \\
\hline $\mathrm{n} / \mathrm{a}$ & $\downarrow$ & 1.5 & Isotocin 2 & n/a & NM_001123652 \\
\hline $\mathrm{n} / \mathrm{a}$ & $\uparrow$ & 1.2 & Melanin-concentrating hormone 2 & n/a & M25755 \\
\hline GT145268 & $\downarrow$ & 1.2 & MHC class I & 0.0 & AF504013 \\
\hline GT145243 & $\downarrow$ & 1.2 & MHC class I & 0.0 & AF504016 \\
\hline FE963873 & $\downarrow$ & 1.2 & ${ }^{4}$ Myelin PO-like glycoprotein & 7E-90 & NM_001140077 \\
\hline GR209337 & $\downarrow$ & 1.2 & Myosin-9 (putative) & 0.0 & BT072044 \\
\hline G0944099 & $\uparrow$ & 1.2 & Phosphogluconate dehydrogenase & $2 \mathrm{E}-94$ & BT059099 \\
\hline CR944012 & $\downarrow$ & 1.3 & Phosphoglycerate mutase 1 & $2 \mathrm{E}-64$ & CX249369 (Omy.36005) \\
\hline GO256580 & $\uparrow$ & 1.2 & Proline-rich nuclear receptor coactivator 2 & 0.0 & NM_001140247 \\
\hline CR944197 & $\uparrow$ & 1.3 & Reverse transcriptase-like protein & 0.0 & CR944197 \\
\hline BM413842 & $\downarrow$ & 1.2 & 60S Ribosomal protein L13A & 0.0 & BT044039 \\
\hline CR943861 & $\downarrow$ & 1.2 & S100 calcium binding protein & 0.0 & NM_001146376 \\
\hline BM413745 & $\downarrow$ & 1.2 & Simple type II keratin K8 & 0.0 & NM_001124734 \\
\hline BF228584 & $\uparrow$ & 1.4 & Suppressor of G2 allele of SKP1 & 0.0 & BT071868 \\
\hline BF228584 & $\downarrow$ & 1.3 & Suppressor of G2 allele of SKP1 & 0.0 & BТ071868 \\
\hline
\end{tabular}


Table 3: Differentially expressed genes of the brain during precocious maturation. (Continued)

\begin{tabular}{llllll}
\hline n/a & $\uparrow$ & 1.2 & TGFB2 & n/a & Aj318936 \\
\hline GO256586 & $\downarrow$ & 1.2 & VAMP-2 & E-176 & CA060527 Ssa.21646 \\
\hline n/a & $\downarrow$ & 1.7 & Vasotocin-1 & n/a & DY736376 \\
\hline n/a & $\downarrow$ & 1.9 & Vasotocin-1 & n/a & DY736376 \\
\hline
\end{tabular}

See footnotes to Table 1. In addition:

${ }^{4}$ First 539bp do not align to myelin P0-like glycoprotein (S. salar): 318/321 (99\%) align to S. salar EST GE77456

genes showing significant differential regulation $(\mathrm{P}<$ 0.01 ) between the precocious and non-precocious brain samples, 23 also showed significant differential expression between one of the biological replicates, i.e. PB1 v PB2 (12 clones) or NPB1 v NPB2 (11 clones). This is possibly a symptom of the small expression changes and subsequent limitations of the analysis; however $84 \%$ of the genes were still unique to the precocious versus non-precocious comparison. From a physiology perspective it could also be argued that the brain has multiple roles to play at any one time and is therefore more affected by the environment than the testes. Individual fish may thus, depending on slight variations in conditions such as social status, availability of food, etc., show more variation in brain expression than in gonad expression. Interestingly all eight globin clones were included in the 12 clone overlap with the PB1 v PB2 comparison and isotocin and both vasotocin clones were included in the 11 clone overlap with the NPB1 v NPB2 comparison.

\section{Quantitative PCR on pooled brains}

In order to validate the findings of the microarray analysis on the brain tissue a number of genes were selected and further investigated using real-time quantitative PCR. These qPCR experiments were carried out on pools of five brains (either PB1 or PB2 against NPB2). The reference gene used was ubiquitin (Additional file 2). Changes suggested by microarray analysis were generally confirmed by qRT-PCR, however, unidentified clone $02 \mathrm{~A} 07$ and beta-globin, both of which appeared down-regulated on the array, were shown to be relatively unchanged by qPCR (Table 2). Melanin-concentrating hormone $(\mathrm{MCH})$, which was in the top 100 list, appeared to be up-regulated on the array in precocity. This gene was examined in 5 precocious individuals (PB2 pool) and in 5 non-precocious individuals (NPB2 pool). On average $\mathrm{MCH}$ was up-regulated approximately 1.7 fold in precocious males.

Although many studies of male precocity in salmonids have reported the association of physical features of fish with life trajectories $[4,5]$ it is only recently that a number of papers have reported the use of genomic approaches to investigate genetic changes associated with these life trajectory decisions in salmonids [39-42] and other species $[43,44]$. The array described herein has been generated from clones which have been selected in relevant tissues for their role in processes that are likely to be involved in precocity. SSH is a commonly used molecular technique to enrich for genes differentially expressed between two populations [21]. Here it has been used to enrich for precocity- and maturation-related genes in brain, brain-related and testes tissue. Furthermore, as the parr-smolt transformation and sexual maturation are often considered competing processes, smolting SSH libraries (for brain and related tissues) may also be relevant to precocity.

In all 500 genes were determined to be differentially expressed between precocious and non-precocious gonad pools $(\mathrm{P}<0.05)$ and 142 genes between precocious and non-precocious brain pools $(\mathrm{P}<0.01)$. In both cases there were approximately 3 times more genes down-regulated than were up-regulated. This suggests a turning down of non-essential processes and the turning up of specific pathways. Some patterns of expression suggested the involvement of specific physiological processes. However, both the relatively small number of unambiguously identified genes and the paucity of GO terms for these meant that a thorough $\mathrm{GO}$ analysis was not possible. Gene expression changes in the brain were small but this is reflected by other papers on brain expression [45-47]. It is a common observation that brain expression changes are often less than 2 -fold which has been noted in fish $[45,48]$ and in other species $[49,50]$. Microarrays have been reported before to show smaller changes in expression than the more robust technique of qPCR and indeed we have found this ourselves in related studies [51]. Alternatively, the microarray signal represents all targets that hybridise to the probe whereas qPCR being primer-based may distinguish between different targets and be more discriminatory.

Apolipoprotein E was down-regulated in the brain whereas it had been up-regulated in the gonad (both confirmed by qPCR). It is unlikely that the specific role of ApoE is the same in both brain and testes. ApoE is involved in neural regeneration of the peripheral nervous system through the redistribution of cholesterol [48] therefore it is possible that it is in this role that ApoE affects brain development in the precocious male. 
Down-regulation of both isotocin (confirmed by qPCR) and vasotocin was evident in the brain of precocious male fish, however all three clones representing these genes on the array were also differentially expressed between the two NPB pools $(\mathrm{P}<0.01)$. This suggests some important variation in the ten non-precocious individuals that made up the two pools. Up-regulation of vasotocin, and to a lesser extent isotocin, is more often associated with reproduction especially through the known effects of vasotocin on social behaviour $[52,53]$. However, differences in the effects of vasotocin administration on aggression and/or courtship are clearly seen between fish species with some showing increased and others decreased aggression [54-56]. There are also seasonal variations in transcript levels of both vasotocin and isotocin in, for example, the masu salmon which in addition show changes between immature parr and precocious males [57]. It has been observed that the protein levels of these hormones do not correspond to the levels of their mRNAs - vasotocin transcript levels are low in Nov in immature parr when vasotocin protein levels are near maximal [57]. Furthermore, vasotocin is also involved in osmoregulation, cardiovascular activity, stress and metabolism [58]. Because precocity possibly interferes with normal progress through the parr-smolt transformation, the relative decrease in vasotocin we observe in precocious fish may be linked to an early regulatory effect on osmoregulation, and the variation we observe in the non-precocious individuals may be due to early preparation for smolting in some fish.

Another gene that appeared to be up-regulated (1.2fold) in the brain was melanin-concentrating hormone $(\mathrm{MCH}) . \mathrm{MCH}$ is expressed as a pro-hormone mainly in the hypothalamus and processed in the pituitary where the mature short peptide (17 amino acids in most teleosts) stimulates the aggregation of melanosome in melanophores resulting in the silvering of the fish [59]. This is somewhat at odds with the expected inhibition of silvering in precocious fish where the parr-smolt transformation is delayed. Receptors for $\mathrm{MCH}$ are, however, distributed much more widely than the brain and hypothalamus suggesting that the functional roles of $\mathrm{MCH}$ (which may include regulating food intake) are much more diverse than melanin concentration $[59,60]$. The DNA sequences of the MCH1 and $\mathrm{MCH} 2$ isoforms of Chinook salmon $\mathrm{MCH}$ are very similar and are unlikely to be distinguished on the microarray. Because both $\mathrm{MCH}$ isoform sequences are not available for Salmo salar, two fragments were isolated and sequenced from Salmo salar cDNA using primers based on the Chinook sequences [61]. Quantitative PCR (using primers designed to the two Atlantic salmon fragment sequences) of individual samples from the PB2 and
NPB2 pools showed approximate 1.7-fold up-regulation of $\mathrm{MCH} 1$ and 1.4-fold up-regulation of $\mathrm{MCH} 2$ in the precocious samples. $\mathrm{MCH} 2$ levels $\left(\mathrm{C}_{\mathrm{t}} \sim 34\right)$ were at least 100 times lower than $\mathrm{MCH} 1$ levels $\left(\mathrm{C}_{\mathrm{t}} \sim 26\right)$ so comparisons of $\mathrm{MCH} 2$ levels between individuals were not reliable; however there was still considerable variability in the levels of MCH1 in the ten individuals. An approximate 290-fold difference (Additional file 2) between the highest and the lowest individuals may reflect sampling inconsistency where some specialised regions of the brain may have been mistakenly included (although the pituitary and hypothalamus had been purposefully dissected from all brain samples).

Alpha- and beta-globin gene expression was down-regulated in the precocious brain as they had been in the testes. Surprisingly all eight globin clones were also differentially expressed between the two pools of precocious brains (PB1 and PB2); this was eight of the nine sequenced clones in a list of twelve clones $(\mathrm{P}<0.01)$. Although the melting point curve on qPCR showed a single peak, it was noticeable during the optimisation of beta-globin primers that there were at least two forms amplified. Haemoglobin multiplicity in teleosts is common: embryonic forms give way to adult forms and it also has been suggested that fish which travel great distances across temperature differentials show more multiplicity [62].

There are some interesting similarities and differences between our precocious males and those of AubinHorth [39,41]. Both studies show down-regulation of genes in precocious males was more pronounced than up-regulation; we see down-regulation of glutamine synthetase and RpL13A which ties in with the above study but we also see down-regulation of vasotocin, isotocin and type II keratin K8 which seems at odds with the Aubin-Horth study. Also alpha- and beta-globin are oppositely regulated in both studies. Possibly the differences seen in the two studies relates to the different times of fish sampling which were October for the Aubin-Horth study and three months later in January for our study. We chose to collect both groups of males in January when precocity was externally evident (size, body shape, milt production). In January the testes could therefore be best described as mature, possibly on the point of regression whereas in October they are likely to be recrudescent. Since maturation is controlled by the HPG axis, in October the brain will be signalling the gonads to mature and to begin steroidogenesis, and accompanying this there will ensue a range of behavioural changes. Therefore it is possibly not surprising that the Aubin-Horth study shows up-regulation of genes involved in reproduction and this study shows some opposite effects.

Furthermore, our control group (immature males) may be preparing for the parr-smolt transformation 
(transfer in the first week of May). There may therefore be some changes in brain precocity expression which are confounded by brain smoltification expression. In a separate experiment (White et al., personal communication), the same genes were followed in a brain smolt time-course from January to May. From this it is clear that most of these genes do not change significantly over the period of smoltification and therefore it is unlikely that down-regulation in precocity is really upregulation in smoltification. It is however interesting that in the Aubin-Horth study several genes, including beta-actin, cathepsin $\mathrm{D}$, an elongation factor, beta tubulin and both vasotocin and isotocin, showed relative up-regulation in 'early migratory' fish that also showed up-regulation in our immature parr.

The fish used in this study are from a hatchery-reared stock that has been developed from a small number of originator males and females and should therefore be of relatively homogeneous genotype. We do not necessarily expect that hatchery and wild salmon will behave in the same way. It has been shown that the rearing environment of Atlantic salmon has an effect on gene expression and additionally that this effect interacts with mating tactic [39]. In a study that used a cichlid microarray to compare wild and laboratory reared salmon from the same source it was clear that some differences in expression between immature male brains and precocious brains were dependent on the rearing environment [39]. This in itself suggests that the sneaker tactic/phenotype does not develop by one unique route and therefore that gene expression profiles may differ from one individual to another due to environment. Also it must always be remembered that for many regulators such as isotocin and vasotocin, because of storage, secretion and blood clearance considerations, transcript levels in the brain and gonad may not directly correlate with protein levels in the plasma, and that plasma levels do not necessarily reflect activation of the system as the hormone receptor in the effector tissue may be down-regulated to prevent effects [57]. As noted above, isotocin and vasotocin blood plasma levels may be high leading to activation of a pathway or process but transcript levels could be low because either the hormone was released from stores (not requiring de novo transcription) or a feedback mechanism was down-regulating transcription. It is a complicated issue where the specific biology is known to vary between different fish species and even within species of the family Salmonidae

\section{Conclusions}

A custom-built salmonid cDNA microarray has been used to compare expression changes in the brain and gonad during the process of precocious sexual maturation in Atlantic salmon. Transcriptional regulation in the brain was minor compared to the testes. Microarray analysis suggested a general down-regulation of housekeeping functions and more specific up-regulation of a number of genes. Distinct expression profiles for both brain and gonad will be determined by maturation stage (recrudescent, mature, regressed) and environmental factors. Anti-Mullerian hormone plays a major role in the development of the maturing gonad as too does lipid mobilisation through the apolipoproteins and lipoprotein lipase.

\section{Methods}

\section{Sample collection}

The Marine Institute in Newport, Co.Mayo, provided Atlantic salmon samples. The Marine Institute, Furnace, Newport, Co. Mayo is a registered premises under the Cruelty to Animals Act 1876, as amended by EU Regulations $2002 \& 2005$ and is declared to be a registered place for the performance of experiments. The Burrishoole ranch stock used in this study were originally derived from Burrishoole wild stock and have been line bred since the early 1970's as part of an on-going experimental ranching programme.

At sampling, fish were transferred to an anaesthetic/ sedative solution (ethyl 4-aminobenzoate; $0.1 \mathrm{~g} / \mathrm{l}$; SigmaAldrich) and killed by spinal section. Fifty precocious male parr and fifty non-precocious male parr (sex determined on dissection) were sampled in January 2003 to provide brain and gonad tissue for SSH library construction. Length and weight measurements were taken. Additional fish for microarray and qRT-PCR analysis were harvested in January 2004. Adult salmon were sampled from upstream traps located on the Burrishoole river system on 31 July 2003 and 25 November 2003 these were tagged therefore are hatchery-reared fish (not wild). The gonadosomatic index (GSI) - the ratio of the weight of the gonad to that of the whole fish (x 100) - for the July fish was $0.19 \pm 0.04$ standard deviations (SD) and for the November fish was $2.44 \pm$ $0.45 \mathrm{SD}$. All tissues were removed to RNAlater or snap frozen in liquid nitrogen. Samples were stored at $-80^{\circ} \mathrm{C}$ until RNA extraction.

\section{Extraction and analysis of RNA}

All samples were lysed and homogenized in TRIzol reagent (Invitrogen Life Technologies, Paisley, UK) [63]. Qiagen RNeasy midi columns and wash buffers (Qiagen Ltd., West Sussex, UK) were used to purify the RNA. All samples were DNase treated on-column using the Qiagen DNA-free DNase Kit (Qiagen Ltd., West Sussex, UK). The concentrations of the RNA samples were determined by UV spectrophotometry (Shimadzu UV1601 or Eppendorf BioPhotometer) and checked for quality using the Agilent Bioanalyser-derived RNA 
integrity number (RIN) (Agilent Technologies Ireland Ltd., Dublin, Ireland) and by denaturing formaldehyde gel electrophoresis followed by northern blotting and subsequent analysis with a radiolabelled beta-actin probe.

\section{Construction of Suppression Subtractive Hybridisation (SSH) cDNA libraries}

Tissues used for the SSH libraries were brain, pituitary, hypothalamus, head kidney, spleen, intestine, gill, testes and ovary. Libraries related to this paper were from brain, pituitary, hypothalamus and testes tissues comparing male parr to precocious parr. Other SSH libraries of relevance compared the ovary of maturing adult females (July) and near maturity females (November). Other SSH libraries to be described elsewhere relating to the parr-smolt transformation were of brain (Feb v sea cage), hypothalamus (Feb v Apr), pituitary (Feb v Apr, Apr v sea cage), gill (Apr v May), and intestine, head kidney and spleen (Feb v May). Exact dates were 13 Feb, 4 Apr, 2 May and 27 May (sea cage) 2003. An additional library pair related to the post-blastula transition of the salmon embryo.

For testes tissue pools of precocious parr and non-precocious parr total RNA were each prepared from 10 individual fish. For brain tissue pools of precocious parr and non-precocious parr total RNA were each prepared from 4 individual fish. For hypothalamus tissue pools of precocious parr were prepared from 3 individual fish and non-precocious parr from 3 pools each of 3 fish (29 Jan). For pituitary tissue pools of precocious parr and non-precocious parr total RNA were each prepared from 10 individual fish (29 Jan and 13 Feb respectively).

The ovarian library from maturing adults and the brain library from smolting parr were made directly from mRNA isolated from total RNA using the Oligotex mRNA Isolation Kit (Qiagen, UK). All other libraries were made from SMART cDNA generated by reverse transcribing $1 \mu \mathrm{g}$ of total RNA as detailed in the SMART cDNA Synthesis Kit (BD Biosciences, Oxford, UK). The PCR-Select cDNA Subtraction Kit (BD Biosciences, Oxford, UK) was subsequently used to prepare both forward and reverse subtracted libraries from each tissue. Subtracted target cDNA products were ligated into the pCR2.1 TA Cloning Vector (Invitrogen Life Technologies, Paisley, UK) using T4 DNA ligase (New England Biolabs) according to the manufacturer's instructions. Ligations were transformed into Ultracomp $^{\text {tw }}$ One-Shot Top 10F' chemically competent E. coli cells (Invitrogen Life Technologies, Paisley, UK). Recombinant white clones from each library (four 96-well plates for each library) were randomly selected from the plates, cultured in LB broth in 96-well plates and frozen in glycerol for archival storage at $-80^{\circ} \mathrm{C}$. Clones were
PCR amplified using 2.5 units of Biotaq (Bioline, UK) in a total volume of $75 \mu \mathrm{l}$ detergent-less buffer $(30 \mathrm{mM}$ Tricine, $\mathrm{pH} 8.0$ containing $50 \mathrm{mM} \mathrm{KCl}, 2 \mathrm{mM} \mathrm{MgCl}$, $0.2 \mathrm{mM}$ dNTPs and $0.2 \mu \mathrm{M}$ of each $\mathrm{SSH}$ nested primer). PCR products were checked for single products on ethidium bromide stained agarose gels and spotted directly.

\section{Microarray design and construction}

The cDNA microarray contained clones from a number of Suppression Subtractive Hybridisation (SSH) cDNA libraries [21] constructed from different salmon tissues at different developmental stages related to sexual maturation, smoltification and embryo development. Of the 5376 cDNA clones, 4128 were newly generated subtracted cDNA clones and the remaining 1248 clones were other SSH or full-length clones from related salmonid projects. All SSH clones average $600-900$ bp in length. Several candidate genes and controls were also included. At the printing stage DNA sequences were only known for those clones that were used to check library quality/redundancy and for those clones that originated from related salmonid projects. Otherwise clones were only sequenced after microarray analysis had identified a differentially expressed gene. The top 100 clones approximately from each of the two microarray analyses detailed here, and the same for additional analyses to be detailed elsewhere, were sequenced (AGOWA, Berlin, Germany). Sequences were edited to remove vector and adaptor sequences, and analysed by BlastN and BlastX algorithms against the NCBI databases of non-redundant nucleic acids and the protein and EST accession databases http://www.ncbi.nlm.nih. gov/BLAST/[64]. BlastN was also carried out against the TIGR database http://compbio.dfci.harvard.edu/tgi/ cgi-bin/tgi/Blast/index.cgi.

The printing onto amino-silane coated glass slides was carried out at the Liverpool Microarray Facility (University of Liverpool, UK) and consisted of duplicate arrays with sub-arrays in a $4 \times 4$ format with 336 spots per sub-array. The composition of the microarray by tissue and developmental stage is given in Figure 4. The array platform has been submitted to Gene Expression Omnibus with accession numbers GPL8731 (10752 features) and GPL8704 (5376 features): the duplicate features in the gonad analysis were not averaged where they were for the brain analysis, hence the two platforms.

\section{Hybridisation design}

Non-precocious parr testes were small and collected in pools of ten. Precocious testes were more substantial and were RNA extracted individually. To compare testes samples precocious parr testes RNAs were pooled in three pools of four individuals and compared in an optimised 


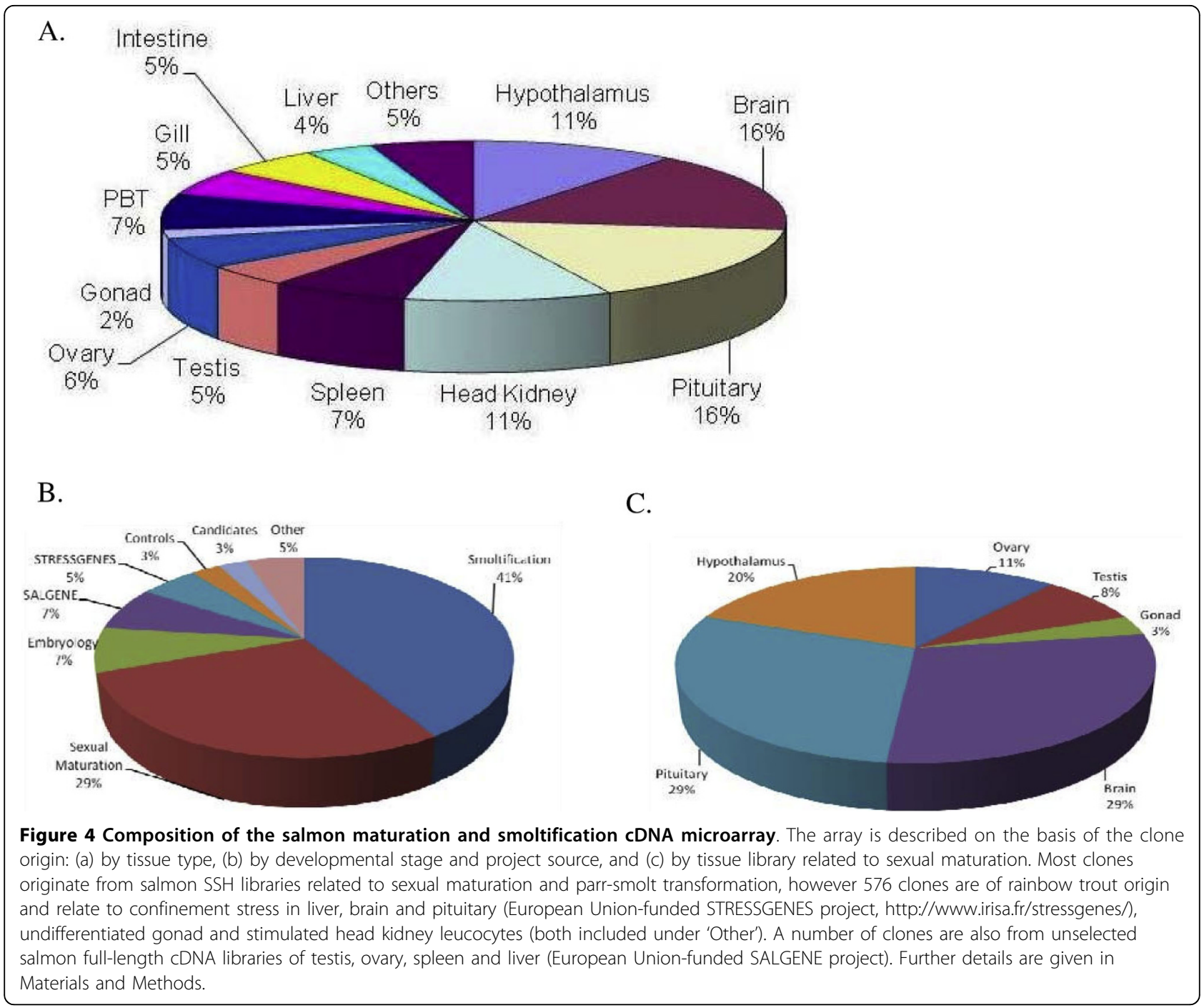

loop design http://www.math.rug.nl/ ernst/book/smida. html[65] to three pools of ten non-precocious parr (Figure 2a). Nine microarray hybridisations were carried out in total as part of this design. To compare brain samples total RNA from 10 individual brains (dissected for hypothalamus and pituitary) of precocious fish and 10 brains of non-precocious fish were pooled to give two pools each of five precocious (PA and $\mathrm{PB}$ ) and nonprecocious (NPA and NPB) brains. Each pool of precocious brains was compared in a dye swap experiment with each pool of non-precocious brains (Figure $2 b$ ).

An indirect labelling method was used to attach Cy5 and $\mathrm{Cy} 3$ dyes to the cDNA. All target cDNAs were synthesised in one round. $10 \mu \mathrm{g}$ of both tester and reference total RNA was used per hybridisation. cDNA was generated by reverse transcription using an anchored oligo $\mathrm{VdT}_{26}$, random primer (V9) and Stratascript RT enzyme. Amino-allyl (aa) dUTP/dNTPs produced from a $20 \times 1: 1$ stock of $\mathrm{dUTP} / \mathrm{dTTP}$ were incorporated into the cDNA. This 1:1 ratio of dUTP/dTTP proved to be an effective ratio for the testes tissue. Contaminating enzymes and buffers were removed by purification with the Nucleospin PCR Clean-up Kit (Macherey-Nagel, Ger). Eluted cDNA was concentrated using a Vacufuge Concentrator 5301 at $42^{\circ} \mathrm{C}$ (Eppendorf, Ger). The resulting cDNA pellets were resuspended in $5 \mu \mathrm{l}$ of sodium bicarbonate $(0.1 \mathrm{M})$ (Sigma Aldrich). Cy dyes were resuspended in the same buffer and coupling to the $\mathrm{Cy}$ dye ester took place in the dark for $2 \mathrm{~h}$ at room temperature. The removal of unincorporated dye was performed using the Illustra CyScribe GFX Purification Kit (GE Healthcare). After coupling the amino-allyl (aa) dUTP-labelled cDNA to the Cy dyes (Amersham Pharmacia Biotech, UK), the labelled cDNA was again purified to remove any un-coupled Cy dye (Macherey Nagel, Ger). Slides were pre-hybridised in $50 \%$ formamide, 
Table 4 Primer list

\begin{tabular}{|c|c|c|c|c|}
\hline Gene & Accession & Primer species & Primer & Primer sequences \\
\hline \multirow[t]{2}{*}{ Anti Mullerian Hormone } & AY722411 & S.salar & $\mathrm{AMHF}$ & ACAAGTGTTCGATCCAGACGTGAC \\
\hline & & & $\mathrm{AMHR}$ & CACTCAGTCTGCCTTGGTGTGG \\
\hline \multirow[t]{2}{*}{ Elongation factor 1 alpha } & AF321836 & S.salar & EF1aF & TAAGGGCAACAGCAGTGGCAGTG \\
\hline & & & EF1aR & CGCATTTGTAGATCAGATGGCCG \\
\hline \multirow[t]{2}{*}{ Beta-globin } & BT050121 & S.salar & BGF & CCCATGGCTGCGACAACCACTTTC \\
\hline & & & BGR & CAACACACTCTTCGTCGACCCTGAC \\
\hline \multirow[t]{2}{*}{ Beta-2-microglobulin } & NM_001123699 & S.salar & RTB2F & GTACTTGTGCTCATTTACAGCGCGG \\
\hline & & & RTB2R & GCCACTCACGTGACAGATCAGGG \\
\hline \multirow[t]{2}{*}{${ }^{1}$ Type 1 collagen } & BE518482 & S.salar & $\mathrm{T} 1 \mathrm{C} 1 \mathrm{~F}$ & GAGGCAATGACCGATGGCTTC \\
\hline & & & $\mathrm{T} 1 \mathrm{C} 1 \mathrm{R}$ & GCGATGCTGTTCTTGCAGTGG \\
\hline \multirow[t]{2}{*}{ Cathepsin B } & EG934102 & S.salar & CatBF & TGTGAGACTGGATACACACCTGGCTAC \\
\hline & & & CatBR & GCTCCTTCCACAGGTCCGTTCTTC \\
\hline \multirow[t]{2}{*}{ Guanine nucleotide binding protein } & BT048931 & S.salar & GNBPF & GTCGCCAAAATGACCGAGCAG \\
\hline & & & ${ }^{2}$ GNBPR & GTCTCATCACGGGTCAACTTCCAC \\
\hline \multirow[t]{2}{*}{ Lipoprotein lipase } & EG868885 & S.salar & LIPF & CGGCCCGACCTTTGAGTTG \\
\hline & & & LIPR & TTGGGGTAGATGTCCACGTGGC \\
\hline \multirow[t]{2}{*}{ Apolipoprotein E } & NM_131098 & D. rerio & ApoEF & TCTCTTGTGGTATTCTTTGCCCTGG \\
\hline & & & ApoER & GTTCAGACACATACTGCCAGAAACGG \\
\hline \multirow[t]{2}{*}{ Calponin 3} & BC053309 & D. rerio & Cal3F & GCAACTGTGATTITACTGCAACTITAGGAC \\
\hline & & & Cal3R & CAATCTTGTTITTCACCTCCGCG \\
\hline \multirow[t]{2}{*}{ Isotocin 1} & ВТ049938 & S.salar & SsIT1F & AAAGCCTCAACCTCAACACATGGC \\
\hline & & & SsIT1R & CTGGATGGGAAAGCTAGTGCTGA \\
\hline \multirow[t]{2}{*}{ Isotocin 2} & CA063528 & S.salar & SsIT2F & TCAGTAAATGGGTGGGTGAAATAGGTG \\
\hline & & & SsIT2R & AGCTGCAAGTGACGCCAGGGT \\
\hline \multirow[t]{2}{*}{ 02A07 } & FD425665 & S.salar & 02A07F & ACCATGTTGACAGCCAGTTTGCG \\
\hline & & & 02A07R & TTCCGCACTCTCAAGCTCACCAC \\
\hline \multirow[t]{2}{*}{$04 \mathrm{H} 01$} & GT145175 & S.salar & $04 \mathrm{H} 01 \mathrm{~F}$ & ACTGTAGTAGTCAGCTTGTGAAGGATGC \\
\hline & & & 04H01R & GTAGTTCCATAGACAGAGAATGGATGCTC \\
\hline \multirow[t]{2}{*}{ 22D02 } & FD425557 & S.salar & $22 \mathrm{D} 02 \mathrm{~F}$ & CAGCTGCTAATACAGGGTTATTGTTTG \\
\hline & & & $22 \mathrm{D} 02 \mathrm{R}$ & CACGTITATGACAACTGACACGTG \\
\hline \multirow[t]{2}{*}{${ }^{3} \mathrm{MCH} 1$} & M25754 & O.tshawytscha & $\mathrm{MCH} 1 \mathrm{~F}$ & AAGAGGCCGACCAGGACCTGA \\
\hline & & & $\mathrm{MCH} 1 \mathrm{R}$ & ACTCAAGATGAGGCAGGACAAGATGC \\
\hline \multirow[t]{2}{*}{$\mathrm{MCH} 2$} & M25755 & O.tshawytscha & $\mathrm{MCH} 2 \mathrm{~F}$ & TCCCCATCGGAAAGACGGAG \\
\hline & & & $\mathrm{MCH} 2 \mathrm{R}$ & TTCAGGTTCATCCACAGGCCA \\
\hline \multirow[t]{2}{*}{ Ubiquitin } & ВТ060103 & S.salar & UBQF & CCACAAAAAGCACCAAGCCAAC \\
\hline & & & UBQR & AGCTGGCCCAGAAGTACAACTGTG \\
\hline \multirow[t]{2}{*}{ Beta-actin } & NM_001123525 & S.salar & ACTF & ATGGAAGATGAAATCGCCG \\
\hline & & & ACTR & CCCTCTTGCTCTGAGCCTCG \\
\hline \multirow[t]{2}{*}{ Succinate de-hydrogenase } & NM_001141694 & S.salar & SUCDEF & GAGGGAAAGGAACAATACCATCAGACTG \\
\hline & & & SUCDER & GACAGCAGGTCCCAGGTACTTGTCTC \\
\hline
\end{tabular}

\section{${ }^{1}$ BE518482 is collagen $1 \mathrm{~A} 1$}

${ }^{2} \mathrm{GNBP}$ : there is one mismatch here to the salmon sequence

${ }^{3} \mathrm{MCH} 1$ and $\mathrm{MCH} 2$ nomenclature is based on the Chinook salmon (O.tshawytscha) $\mathrm{MCH}$ sequences 
$5 \times \mathrm{SSC}, 0.1 \%$ SDS, $0.1 \mathrm{mg} / \mathrm{ml} \mathrm{BSA}$ at $42^{\circ} \mathrm{C}$ for $1 \mathrm{~h}$, then washed twice for $5 \mathrm{~min}$ with $0.1 \times \mathrm{SSC}$ and for $30 \mathrm{~s}$ with $18 \mathrm{M} \Omega \mathrm{H}_{2} \mathrm{O}$. The slides were dried immediately by centrifugation (Eppendorf Multipurpose Centrifuge 5804) at $1500 \mathrm{rpm}$ for $5 \mathrm{~min}$ at room temperature in a slide box lined with $3 \mathrm{MM}$ Whatman paper. The denatured $\mathrm{Cy}$ dye-labelled cDNA was immediately applied to the slides. The purified, combined Cy5- and Cy3-labelled cDNAs were denatured at $95^{\circ} \mathrm{C}$ in a thermal cycler for 3 min. Dust was removed from the surface of the prehybridised arrays using an ozone-free air duster (Kenair, UK). Denatured target cDNA ( $80 \mu \mathrm{l})$ was applied to the array surface which was covered with a lifter slip (Erie Scientific, USA). Each array was placed in a pre-warmed Genetix hybridisation chamber. The chamber was sealed and incubated in an oven for $16-18 \mathrm{~h}$ at $50^{\circ} \mathrm{C}$. Microarray wash solutions were warmed to $55^{\circ} \mathrm{C}$. All wash steps were carried out in the dark. Each array was dipped in a $50 \mathrm{ml}$ conical tube filled with wash solution $1(2 \times \mathrm{SSC}$, $0.1 \%$ SDS) to dislodge the cover-slip. The arrays were washed twice for $5 \mathrm{~min}$ on a rotary table in fresh wash solution 1 . The arrays were transferred to wash solution $2(0.1 \times$ SSC $)$ and washed twice for 1 min on a rotary table. Finally, the arrays were rinsed by immersion in RNase/DNase-free water to remove any residual salts, followed by brief immersion in 100\% isopropanol (Sigma-Aldrich) at room temperature and brief centrifugation at $1500 \mathrm{rpm}$ for $2 \mathrm{~min}$ to dry the slides. The arrays were scanned as soon as possible after washing.

\section{Microarray scanning and analysis}

After hybridisation, fluorescence was measured using a confocal laser scanner (ScanArray Express HT, Perkin Elmer, USA). The high-resolution images were inspected using Genepix Pro v5.1.0.16 (gonad data) or Genepix Pro v6.0.1.25 (brain data) (Molecular Devices, USA). The LIMMA package for analysis of gene expression microarray data was used for both experiments [23,24]. For this spots were weighted based on feature flagging in Genepix: weak signal and feature irregularity appeared to be the main source of discrepancy therefore features were flagged to avoid these spots. Poor quality spots were assigned a weight of 0.1 whereas remaining good quality spots were given a weight of 1.0. For the gonad analysis median local background values were subtracted directly from median feature values, dye channels were swapped as appropriate and a 'printtiploess' normalisation (within slide) was applied. For the brain analysis background subtraction used the "normexp" method in LIMMA with an offset of 50, otherwise the treatment of data was the same as for the gonad experiment. LIMMA uses an empirical Bayes method for improved power in designs which only include a small number of arrays [23].
Different design models in LIMMA allowed a global comparison of the precocious and non-precocious gonads but, in addition, the different pools (i.e. 1 to 3 ) could be compared to each other: this was of interest as it could highlight any variation (either technical or biological) between individual samples. For the gonad analysis we chose to treat duplicates individually and only where both spots were significant $(\mathrm{P}<0.05)$ was the spot accepted. This will tend to increase the number of false negatives but decrease the number of false positives. For the brain analysis we chose to average the MA values for duplicate spots.

\section{Quantitative PCR}

Real-time PCR using SYBR Green-based detection was carried on the Mx3000P Real-Time PCR System (Stratagene). PCR primers (MWG Biotech, Ger) were designed according to the recommended guidelines in the QuantiTect SYBR Green PCR handbook (Qiagen Ltd., West Sussex, UK) and are provided in Table 4. All primer products and PCR conditions were first optimised using standard PCR with electrophoresis on ethidium bromide-stained agarose gels. cDNA was generated by reverse transcription of $1 \mu \mathrm{g}$ total RNA (whether as a pool or individual) using an anchored oligo $\mathrm{VdT}_{26}$ random primer (V9) and Stratascript RT enzyme in a total volume of $20 \mu \mathrm{l}$ following the manufacturer's protocol. cDNA was diluted to $100 \mu \mathrm{l}$ before use as a template for qPCR. Initial analysis of gene expression was carried out on pooled individual cDNA samples. Technical variation was minimised by reverse transcribing all samples at the same time. The analysis was then carried out on individual cDNA samples in triplicate for each gene of interest. PCR data (as threshold cycle (Ct) numbers) were imported into Excel where the $2^{\wedge}$-DeltaDeltaCt formula [36] was applied. This data was then imported into the GraphPad InStat programme (version 3.0) for statistical analysis. (Additional file 2).

\footnotetext{
Additional file 1: Full version of Table 1 (Table 1s). Differentially

expressed genes of the testis during precocious maturation. This version includes additional clones that were not definitively identified and includes two additional columns detailing clone library origin and sequence homology information.

Additional file 2: Selection of housekeeping genes for testis and brain tissue. Further details of how $\mathrm{qPCR}$ analysis was carried out routinely and a discussion of how housekeeping genes were selected for testis and brain tissue. Also further details of the MCH1 and MCH2 qPCR analyses of individual brain samples are provided.

Additional file 3: Full version of Table $\mathbf{3}$ (Table 3s). Differentially expressed genes of the brain during precocious maturation. This version includes additional clones that were not definitively identified and includes two additional columns detailing clone library origin and sequence homology information.
} 


\section{Acknowledgements}

We would like to thank Jennifer Larkin and Thomas Reynolds for technical assistance in QRT-PCR analysis and SSH library construction, and Dr Emma Holian for her help with the LIMMA analysis. Also thanks to Prof Andrew Cossins (University of Liverpool) for the use of their microarray printing facilities and Dr Margaret Hughes for printing. This project was funded by the Higher Education Authority (HEA) of Ireland under PRTLI Cycle 3. Additional work and support for MTC and BH was funded through Enterprise Ireland.

\section{Author details}

${ }^{1}$ National University of Ireland, Galway, University Road, Galway, Ireland. ${ }^{2}$ Marine Institute, Furnace, Newport, Co Mayo, Ireland.

\section{Authors' contributions}

AG and DF carried out the microarray studies. AG, DF, SH, AMOK, SLW and PFF were involved in the weighing, measurements and gonadal index determination of the precocious fish. AG, DF, SH, AMOK, SLW and PFF prepared and characterised the SSH libraries. AG, BH and PD carried out the qRT-PCR. DC provided the fish, the facilities to dissect these and background expertise on these fish populations. SH and AMOK organised the logistics of the array construction. OLP provided software and bioinformatics help throughout. TJS was academic supervisor to AG and guided her role in the work. MTC and NPW conceived of the study, and participated in its design and coordination and drafted the manuscript. MTC carried out all LIMMA analysis. All authors read and approved the final manuscript.

Received: 23 October 2009 Accepted: 30 March 2010

Published: 30 March 2010

\section{References}

1. Taborsky M: The Evolution of Bourgeois, Parasitic, and Cooperative Reproductive Behaviors in Fishes. J Hered 2001, 92(2):100-110.

2. Gross MR: Sneakers, satellites and parentals - polymorphic mating strategies in North-American sunfishes. Zeitschrift Fur TierpsychologieJournal of Comparative Ethology 1982, 60(1):1-26.

3. Gross MR: Alternative reproductive strategies and tactics: diversity within sexes. Trends in Ecology \& Evolution 1996, 11(2):92-98.

4. Fleming IA: Pattern and variability in the breeding system of Atlantic salmon (Salmo salar), with comparisons to other salmonids. International Workshop on Integrating Across Scales - Predicting Patterns of Change in Atlantic Salmon: Mar 1997; Braemar, Scotland Natl Research Council Canada 1997, 59-76.

5. Letcher $\mathrm{BH}$, Gries $\mathrm{G}$ : Effects of life history variation on size and growth in stream-dwelling Atlantic salmon. Journal of Fish Biology 2003, 62(1):97-114.

6. Hutchings JA, Myers RA: The evolution of alternative mating strategies in variable environments. Evolutionary Ecology 1994, 8(3):256-268.

7. Hutchings JA: Norms of reaction and phenotypic plasticity in salmonid life history. Oxford: Oxford University Press 2004.

8. Naevdal G, Holm M, Moller D, Osthus OD: Variation in growth rate and age at sexual maturity in Atlantic salmon. ICES CM 1976, E:40.

9. Glebe BD, Saunders RL: Genetic factors in sexual maturity of cultured Atlantic salmon (Salmo salar) parr and adults reared in sea cages. Can Spec Publ Fish Aquat Sci 1986, 89:24-29.

10. Piche J, Hutchings JA, Blanchard W: Genetic variation in threshold reaction norms for alternative reproductive tactics in male Atlantic salmon, Salmo salar. Proceedings of the Royal Society B-Biological Sciences 2008, 275(1642):1571-1575.

11. Baum D, Laughton $R$, Armstrong JD, Metcalfe NB: Altitudinal variation in the relationship between growth and maturation rate in salmon parr. Journal of Animal Ecology 2004, 73(2):253-260.

12. Jordan WC, Youngson AF: The use of genetic marking to assess the reproductive success of mature male Atlantic salmon parr (Salmo salar, L) under natural spawning conditions. Journal of Fish Biology 1992, 41(4):613-618.

13. Garcia-Vazquez E, Moran P, Martinez JL, Perez J, de Gaudemar B, Beall E: Alternative mating strategies in Atlantic salmon and brown trout Symposium on DNA-Based Profiling of Mating Systems and Reproductive Behaviors in Poikilothermic Vertebrates: Jun 17-20 2000; New Haven, Ct Oxford Univ Press Inc 2000, 146-149.
14. Folstad I, Karter AJ: Parasites, Bright Males, and the Immunocompetence Handicap. The American Naturalist 1992, 139(3):603.

15. Metcalfe NB, Thorpe JE: Determinants of geographical variation in the age of seaward migrating salmon, Salmo salar. Journal of Animal Ecology 1990, 59(1):135-145.

16. Thorpe JE, Talbot C, Villarreal C: Bimodality of growth and smolting in Atlantic salmon, Salmo salar L. Aquaculture 1982, 28(1-2):123-132.

17. Rise ML, von Schalburg KR, Brown GD, Mawer MA, Devlin RH, Kuipers N, Busby M, Beetz-Sargent M, Alberto R, Gibbs AR, et al: Development and Application of a Salmonid EST Database and cDNA Microarray: Data Mining and Interspecific Hybridization Characteristics. Genome Research 2004, 14(3):478-490.

18. Calduch-Giner JA, Davey G, Saera-Vila A, Houeix B, Talbot A, Prunet P, Cairns MT, Pérez-Sánchez J: Use of microarray technology to assess the time course of liver stress response after confinement exposure in gilthead sea bream (Sparus aurata L.). BMC Genomics 2010.

19. Rowe DK, Thorpe JE: Differences in growth between maturing and nonmaturing male Atlantic salmon, Salmo salar L, parr. Journal of Fish Biology 1990, 36(5):643-658

20. Muellar O, Lightfoot S, Schroeder A: RNA integrity number (RIN)standardization of RNA quality control. Agilent Application Note 2004, 1-8, Publication 5989-1165EN.

21. Diatchenko L, Lau YF, Campbell AP, Chenchik A, Moqadam F, Huang B, Lukyanov S, Lukyanov K, Gurskaya N, Sverdlov ED, et al: Suppression subtractive hybridization: a method for generating differentially regulated or tissue-specific CDNA probes and libraries. Proc Natl Acad Sci USA 1996, 93(12):6025-6030.

22. Davey GC, Caplice NC, Martin SA, Powell R: A survey of genes in the Atlantic salmon (Salmo salar) as identified by expressed sequence tags. Gene 2001, 263(1-2):121-130.

23. Smyth GK: Linear Models and Empirical Bayes Methods for Assessing Differential Expression in Microarray Experiments. Statistical Applications in Genetics and Molecular Biology 2004, 3(1), Article 3.

24. Smyth GK, Michaud J, Scott HS: Use of within-array replicate spots for assessing differential expression in microarray experiments. Bioinformatics 2005, 21(9):2067-2075.

25. Mead J, Irvine S, Ramji D: Lipoprotein lipase: structure, function, regulation, and role in disease. Journal of Molecular Medicine 2002, 80(12):753-769.

26. Nielsen JE, Lindegaard ML, Friis-Hansen L, Almstrup K, Leffers $H$, Nielsen LB, Meyts ER-D: Lipoprotein lipase and endothelial lipase in human testis and in germ cell neoplasms. International Journal of Andrology 2009.

27. Lane $\mathrm{AH}$, Donahoe PK: New insights into mullerian inhibiting substance and its mechanism of action. J Endocrinol 1998, 158(1):1-6.

28. Klüver N, Pfennig F, Pala I, Storch K, Schlieder MAF, Gutzeit HO, M S: Differential expression of anti-Müllerian hormone (AMH) and antiMüllerian hormone receptor type II (AMHRII) in the teleost medaka. Developmental Dynamics 2007, 236(1):271-281.

29. Miura T, Miura C, Konda Y, Yamauchi K: Spermatogenesis-preventing substance in Japanese eel. Development 2002, 129(11):2689-2697.

30. Rolland A, Lareyre J-J, Goupil A-S, Montfort J, Ricordel M-J, Esquerre D, Hugot K, Houlgatte R, Chalmel F, Le Gac F: Expression profiling of rainbow trout testis development identifies evolutionary conserved genes involved in spermatogenesis. BMC Genomics 2009, 10(1):546.

31. Baron D, Houlgatte R, Fostier A, Guiguen Y: Expression profiling of candidate genes during ovary-to-testis trans-differentiation in rainbow trout masculinized by androgens. General and Comparative Endocrinology 2008, 156(2):369-378

32. Chen CC, Fernald RD: GnRH and GnRH receptors: distribution, function and evolution. Journal of Fish Biology 2008, 73(5):1099-1120.

33. Madigou T, Uzbekova S, Lareyre JJ, Kah O: Two messenger RNA isoforms of the gonadotrophin-releasing hormone receptor, generated by alternative splicing and/or promoter usage, are differentially expressed in rainbow trout gonads during gametogenesis. Molecular Reproduction and Development 2002, 63(2):151-160.

34. Ma XL, Liu XC, Zhang Y, Zhu P, Ye W, Lin HR: Two growth hormone receptors in Nile tilapia (Oreochromis niloticus): Molecular characterization, tissue distribution and expression profiles in the gonad during the reproductive cycle. Comparative Biochemistry and Physiology BBiochemistry \& Molecular Biology 2007, 147(2):325-339. 
35. Agustsson T, Sundell K, Sakamoto T, Ando M, Bjornsson BT: Pituitary gene expression of somatolactin, prolactin, and growth hormone during Atlantic salmon parr-smolt transformation. Aquaculture 2003, 222(14):229-238.

36. Livak K, Schmittgen TD: Analysis of relative gene expression data using real-time quantitative PCR and the 2(-Delta Delta C(T)) Method. Methods 2001, 25(4):402-408.

37. McCahill A, Warwicker J, Bolger GB, Houslay MD, Yarwood SJ: The RACK1 Scaffold Protein: A Dynamic Cog in Cell Response Mechanisms. Molecular Pharmacology 2002, 62(6):1261-1273.

38. Liu YV, Semenza GL: RACK1 vs. HSP90 - Competition for HIF-1 alpha degradation vs. stabilization. Cell Cycle 2007, 6(6):656-659.

39. Aubin-Horth $\mathrm{N}$, Letcher BH, Hofmann HA: Interaction of rearing environment and reproductive tactic on gene expression profiles in Atlantic salmon. J Hered 2005, 96(3):261-278.

40. Aubin-Horth $\mathrm{N}$, Landry CR, Letcher BH, Hofmann HA: Alternative life histories shape brain gene expression profiles in males of the same population. Proceedings of the Royal Society B-Biological Sciences 2005, 272(1573):1655-1662.

41. Aubin-Horth N, Letcher BH, Hofmann HA: Gene-expression signatures of Atlantic salmon's plastic life cycle. General and Comparative Endocrinology 2009, 163(3):278-284

42. Giger T, Excoffier L, Amstutz U, Day PJR, Champigneulle A, Hansen MM, Kelso J, Largiader Carlo R: Population transcriptomics of life-history variation in the genus Salmo. Molecular Ecology 2008, 17(13):3095-3108.

43. Rios-Cardenas O, Webster MS: A molecular genetic examination of the mating system of pumpkinseed sunfish reveals high pay-offs for specialized sneakers. Molecular Ecology 2008, 17(9):2310-2320.

44. Cummings ME, Larkins-Ford J, Reilly CRL, Wong RY, Ramsey M, Hofmann HA: Sexual and social stimuli elicit rapid and contrasting genomic responses. Proceedings of the Royal Society B: Biological Sciences 2008, 275(1633):393-402

45. Martyniuk CJ, Xiong HL, Crump K, Chiu S, Sardana R, Nadler A, Gerrie ER, Xia XH, Trudeau VL: Gene expression profiling in the neuroendocrine brain of male goldfish (Carassius auratus) exposed to 17 alphaethinylestradiol. Physiological Genomics 2006, 27(3):328-336.

46. Reilly SC, Quinn JP, Cossins AR, Sneddon LU: Novel candidate genes identified in the brain during nociception in common carp (Cyprinus carpio) and rainbow trout (Oncorhynchus mykiss). Neuroscience Letters 2008, 437(2):135-138.

47. Krasnov A, Koskinen H, Pehkonen P, Rexroad CE, Afanasyev S, Molsa H: Gene expression in the brain and kidney of rainbow trout in response to handling stress. BMC Genomics 2005, 6(1):3.

48. Sporis D, Sertic J, Henigsberg N, Mahovic D, Bogdanovic N, Babic T: Association of refractory complex partial seizures with a polymorphism of ApoE genotype. Journal of Cellular and Molecular Medicine 2005, 9(3):698-703.

49. Bosetti F, Bell JM, Manickam P: Microarray analysis of rat brain gene expression after chronic administration of sodium valproate. Brain Research Bulletin 2005, 65(4):331-338.

50. Marvanova M, Lakso M, Wong G: Identification of genes regulated by memantine and MK-801 in adult rat brain by CDNA microarray analysis. Neuropsychopharmacology 2004, 29(6):1070-1079.

51. Cairns MT, Johnson MC, Talbot AT, Pernmasani JK, McNeill RE, Houeix B, Sangrador-Vegas A, Pottinger TG: A cDNA microarray assessment of gene expression in the liver of rainbow trout (Oncorhynchus mykiss) in response to a handling and confinement stressor. Comparative Biochemistry and Physiology D-Genomics \& Proteomics 2008, 3(1):51-66.

52. Goodson JL, Bass AH: Social behavior functions and related anatomical characteristics of vasotocin/vasopressin systems in vertebrates. Brain Research Reviews 2001, 35(3):246-265.

53. Thompson RR, Walton JC: Peptide Effects on Social Behavior: Effects of Vasotocin and Isotocin on Social Approach Behavior in Male Goldfish (Carassius auratus). Behavioral Neuroscience 2004, 118(3):620-626.

54. Greenwood AK, Wark AR, Fernald RD, Hofmann HA: Expression of arginine vasotocin in distinct preoptic regions is associated with dominant and subordinate behaviour in an African cichlid fish. Proceedings of the Royal Society B: Biological Sciences 2008, 275(1649):2393-2402.

55. Semsar K, Kandel FLM, Godwin J: Manipulations of the AVT System Shift Social Status and Related Courtship and Aggressive Behavior in the Bluehead Wrasse. Hormones and Behavior 2001, 40(1):21-31.
56. Lema SC, Nevitt GA: Exogenous vasotocin alters aggression during agonistic exchanges in male Amargosa River pupfish (Cyprinodon nevadensis amargosae). Hormones and Behavior 2004, 46(5):628-637.

57. Ota $Y$, Ando $H$, Ueda $H$, Urano A: Differences in seasonal expression of neurohypophysial hormone genes in ordinary and precocious male masu salmon. General and Comparative Endocrinology 1999, 116(1):40-48.

58. Balment RJ, Lu W, Weybourne E, Warne JM: Arginine vasotocin a key hormone in fish physiology and behaviour: A review with insights from mammalian models. General and Comparative Endocrinology 2006, 147(1):9-16.

59. Kawauchi $\mathrm{H}$ : Functions of melanin-concentrating hormone in fish. Journal of Experimental Zoology Part A: Comparative Experimental Biology 2006, 305A(9):751-760.

60. Pissios P, Bradley RL, Maratos-Flier E: Expanding the scales: The multiple roles of $\mathrm{MCH}$ in regulating energy balance and other biological functions. Endocrine Reviews 2006, 27(6):606-620.

61. Minth CD, Qiu H, Akil H, Watson SJ, Dixon JE: Two precursors of melaninconcentrating hormone - DNA-sequence analysis and in situ and immunochemical localization. Proceedings of the National Academy of Sciences of the United States of America 1989, 86(11):4292-4296.

62. Dettai A, di Prisco G, Lecointre G, Parisi E, Verde C: Inferring evolution of fish proteins: The globin case study. Globins and Other Nitric OxideReactive Proteins, Pt A San Diego: Elsevier Academic Press Inc 2008, 436:539-+

63. Chomczynski P, Sacchi N: The single-step method of RNA isolation by acid guanidinium thiocyanate-phenol-chloroform extraction: twentysomething years on. Nat Protoc 2006, 1(2):581-585.

64. McGinnis S, Madden TL: BLAST: at the core of a powerful and diverse set of sequence analysis tools. Nucleic Acids Res 2004, 32 Web Server: W20-25.

65. Wit EC, McClure JD: Statistics for Microarrays: Design, Analysis and Inference. Chichester: Wiley 2004.

doi:10.1186/1471-2164-11-211

Cite this article as: Guiry et al:: Testes and brain gene expression in precocious male and adult maturing Atlantic salmon (Salmo salar). BMC Genomics 2010 11:211.

\section{Submit your next manuscript to BioMed Central and take full advantage of:}

- Convenient online submission

- Thorough peer review

- No space constraints or color figure charges

- Immediate publication on acceptance

- Inclusion in PubMed, CAS, Scopus and Google Scholar

- Research which is freely available for redistribution

Submit your manuscript at www.biomedcentral.com/submit
C Biomed Central 